Article

\title{
Towards a Monitoring Approach for Understanding Permafrost Degradation and Linked Subsidence in Arctic Peatlands
}

\author{
Betsabe de la Barreda-Bautista ${ }^{1,2}$, Doreen S. Boyd ${ }^{2} \oplus$, Martha Ledger ${ }^{1}$, Matthias B. Siewert ${ }^{3} \oplus$, Chris Chandler ${ }^{2}$, \\ Andrew V. Bradley ${ }^{4}$, David Gee ${ }^{5}$, David J. Large ${ }^{4,5}$, Johan Olofsson ${ }^{3}$, Andrew Sowter ${ }^{6}$ and Sofie Sjögersten ${ }^{1, *}$ \\ 1 School of Biosciences, University of Nottingham, College Road, Sutton Bonington, \\ Loughborough LE12 5RD, UK; lgzbd1@exmail.nottingham.ac.uk (B.d.1.B.-B.); \\ mbxml5@exmail.nottingham.ac.uk (M.L.) \\ 2 School of Geography, University of Nottingham, University Park, Nottingham NG7 2RD, UK; \\ doreen.boyd@nottingham.ac.uk (D.S.B.); lgzcjc@exmail.nottingham.ac.uk (C.C.) \\ 3 Department of Ecology and Environmental Sciences, University of Umeå, KB H4, Linnaeus väg 6, \\ Umeå Universitet, 90187 Umeå, Sweden; matthias.siewert@umu.se (M.B.S.); johan.olofsson@umu.se (J.O.) \\ 4 Department of Chemical and Environmental Engineering, Faculty of Engineering, \\ Nottingham Geospatial Institute, Innovation Park, Jubilee Campus, Nottingham NG7 2TU, UK; \\ ezzavb@exmail.nottingham.ac.uk (A.V.B.); david.large@nottingham.ac.uk (D.J.L.) \\ 5 Department of Chemical and Environmental Engineering, Faculty of Engineering, University of Nottingham, \\ Nottingham NG7 2RG, UK; david.gee@terramotion.co.uk \\ 6 Terra Motion Ltd., Ingenuity Centre, Triumph Rd, Nottingham NG7 2TU, UK; \\ andrew.sowter@terramotion.co.uk \\ * Correspondence: sofie.sjogersten@nottingham.ac.uk
}

Citation: de la Barreda-Bautista, B.; Boyd, D.S.; Ledger, M.; Siewert, M.B.; Chandler, C.; Bradley, A.V.; Gee, D.; Large, D.J.; Olofsson, J.; Sowter, A.; et al. Towards a Monitoring Approach for Understanding Permafrost Degradation and Linked Subsidence in Arctic Peatlands. Remote Sens. 2022, 14, 444. https:// doi.org/10.3390/rs14030444

Academic Editor: Radosław Juszczak

Received: 22 December 2021

Accepted: 14 January 2022

Published: 18 January 2022

Publisher's Note: MDPI stays neutral with regard to jurisdictional claims in published maps and institutional affiliations.

Copyright: (C) 2022 by the authors. Licensee MDPI, Basel, Switzerland. This article is an open access article distributed under the terms and conditions of the Creative Commons Attribution (CC BY) license (https:// creativecommons.org/licenses/by/ $4.0 /)$.

\begin{abstract}
Permafrost thaw resulting from climate warming is threatening to release carbon from high latitude peatlands. The aim of this research was to determine subsidence rates linked to permafrost thaw in sub-Arctic peatlands in Sweden using historical orthophotographic (orthophotos), Unoccupied Aerial Vehicle (UAV), and Interferometric Synthetic Aperture Radar (InSAR) data. The orthophotos showed that the permafrost palsa on the study sites have been contracting in their areal extent, with the greatest rates of loss between 2002 and 2008. The surface motion estimated from differential digital elevation models from the UAV data showed high levels of subsidence (maximum of $-25 \mathrm{~cm}$ between 2017 and 2020) around the edges of the raised palsa plateaus. The InSAR data analysis showed that raised palsa areas had the greatest subsidence rates, with maximum subsidence rates of $1.5 \mathrm{~cm}$ between 2017 and 2020; however, all wetland vegetation types showed subsidence. We suggest that the difference in spatial units associated with each sensor explains parts of the variation in the subsidence levels recorded. We conclude that InSAR was able to identify the areas most at risk of subsidence and that it can be used to investigate subsidence over large spatial extents, whereas UAV data can be used to better understand the dynamics of permafrost degradation at a local level. These findings underpin a monitoring approach for these peatlands.
\end{abstract}

Keywords: permafrost; peatland; InSAR

\section{Introduction}

Permafrost thawing in the Arctic, caused by climate warming, is rapidly accelerating [1], resulting in the release of frozen carbon stocks [2-6] and promoting damaging positive feedbacks, such as increased greenhouse gas emissions [7-9]. Permafrost thaw manifests as surface subsidence and thus detection and quantification of areas experiencing subsidence are key to predicting the magnitude of such feedbacks $[10,11]$. Remote observation is a useful approach to doing so, but accurately predicting the impacts of subsidence over large areas remains elusive [12], mainly because a better understanding between process scale and observation scale is required. This point is addressed here over a palsa peatland environment in northern Sweden. 
Palsa peatlands consist of raised plateaus and are common geomorphological features in the sub-Arctic zones of Eurasia and North America. These landforms contain layers of permafrost, uplifting and protecting accumulated carbon in peat from decomposition. This results in relatively dry surface ground conditions and vegetation of low productivity $[13,14]$. Degradation of palsas and peat plateaus in response to climatic changes typically progresses through lateral erosion along the edges, but also through permafrost active layer deepening and the reduction of permafrost body thickness $[15,16]$. Ground temperature is a key control of permafrost, and local conditions (e.g., snow accumulation) that impact ground temperature contribute to spatial variation in active layer depth and rates of degradation [17-19]. The response of palsa peatlands to warmer conditions or altered snow dynamics has already been observed across northern Scandinavia $[1,18,20,21]$ and elsewhere [22]. Permafrost thaw in peat plateaus is typically reported on decadal timescales as a response to changes in temperature and precipitation conditions $[23,24]$; however, rapid degradation in response to short-term climatic events has been seen to occur $[16,18,20]$. The consequence of this is an overall subsidence of the area (including both vertical ground settlement as a result of active layer deepening, and lateral erosion). Quantifying the rate of this degradation is key to understanding the effects of climate change in the Arctic landscape, as well as to predicting which areas are at risk of becoming carbon sources as they thaw [25].

It is known that permafrost thaw occurs over interconnected remote landscapes across the Arctic, therefore any monitoring of degradation is required over large spatial extents, preferably at the spatial and temporal resolutions that match the patterns of thaw $[1,26,27]$. Satellite optical imagery, polarimetric PALSAR, and aerial orthophotos have been used to monitor features of permafrost thaw-formation of thermokarst lakes, lateral shrinkage of palsa areas, ice-wedge degradation, and vegetation composition change [10,16,27-32] These remote sensing approaches offer important insights into the spatial distribution of permafrost thaw and the impact of this on carbon stocks. However, they are limited by their inability to: (i) detect subsidence (i.e., lowering of the ground surface in response to increasing active layer depth and/or lateral erosion) and/or (ii) provide sufficient temporal and spatial coverage to detect intra- and inter-annual change on landscape scales. Alternative and complimentary approaches are necessary for optimal data supply to fully understand how warming is impacting the palsa peatlands.

Active remote sensing methods have seen some success for the quantification of surface subsidence. Repeated passes of airborne light detection and ranging (LiDAR) have been used to measure top-down permafrost thaw $[33,34]$, but this approach, though highly detailed, is operationally limited to small spatial extents. The monitoring of larger spatial extents for the surface motion of permafrost thaw could be possible through the use of satellite Interferometric SAR (InSAR) methods [35-40], which have the added advantage of overcoming cloud cover that hampers optical satellite systems. SAR data from the Sentinel-1 satellite system, which has the advantage of providing open data, with a return rate of 6 to 12 days, can be processed into surface deformation products to a resolution of tens of metres [41] and thus has the potential for detecting surface motion resulting from permafrost degradation. However, the spatial resolution of InSAR data [42] is larger than the spatial transition in soil structure and permafrost degradation [13,43], and it is not known how well InSAR can detect surface motion palsa peatlands impacted by permafrost degradation.

The overarching aim of this research was to investigate trends of permafrost degradation across three Arctic peatland areas distributed along an east-west transect along the shore of Lake Torneträsk in northern Sweden. A combination of different remote sensing techniques-historical airborne photography; repeated very high resolution (VHR) optical captured by unoccupied aerial vehicles and InSAR using Sentinel-1 data-coupled with field data were used to detect and quantify trends in permafrost degradation. Our linked hypotheses were that areas with shallower active layers (i.e., raised palsa areas with sparse, low statue vegetation) would have the greatest subsidence rates, while areas with deep 
active layers or no permafrost would have lower subsidence rates (e.g., fen type vegetation) as these areas have reached more stable ground surface conditions.

\section{Study Area}

Three peatland locations containing permafrost- - the Tourist Station, Storflaket, and Stordalen wetlands (Figure 1) - situated to the south of Lake Torneträsk, northern Sweden $\left(68^{\circ} 12^{\prime} \mathrm{N}, 19^{\circ} 03^{\prime} \mathrm{E}, 351 \mathrm{~m}\right.$ asl) - were the focus of study. The mean annual temperature (MAT) in the area ranges between 0.8 and $1.0^{\circ} \mathrm{C}$, and the mean annual precipitation (MAP) ranges from $304 \mathrm{~mm}$ in the west to $424 \mathrm{~mm}$ in the east. The initiation of peat formation is ca. 5000 year BP [44]. Total peat depths, including the permanently frozen layer, range from 90 to $200 \mathrm{~cm}[20,44]$. The depth of the active layer (the seasonally thawed upper part of the soil) varies between drier areas, which have a shallower $(\mathrm{ca} .30-60 \mathrm{~cm})$ active layer and wetter areas where the active layer is deeper or where there is no permafrost at all in the upper $1.5 \mathrm{~m}$. In the Torneträsk area, the active layer depths have increased, between 0.2 and $2.0 \mathrm{~cm}_{\text {year }}{ }^{-1}$ over the period 1978-2006, with a higher rate in more recent years [20].

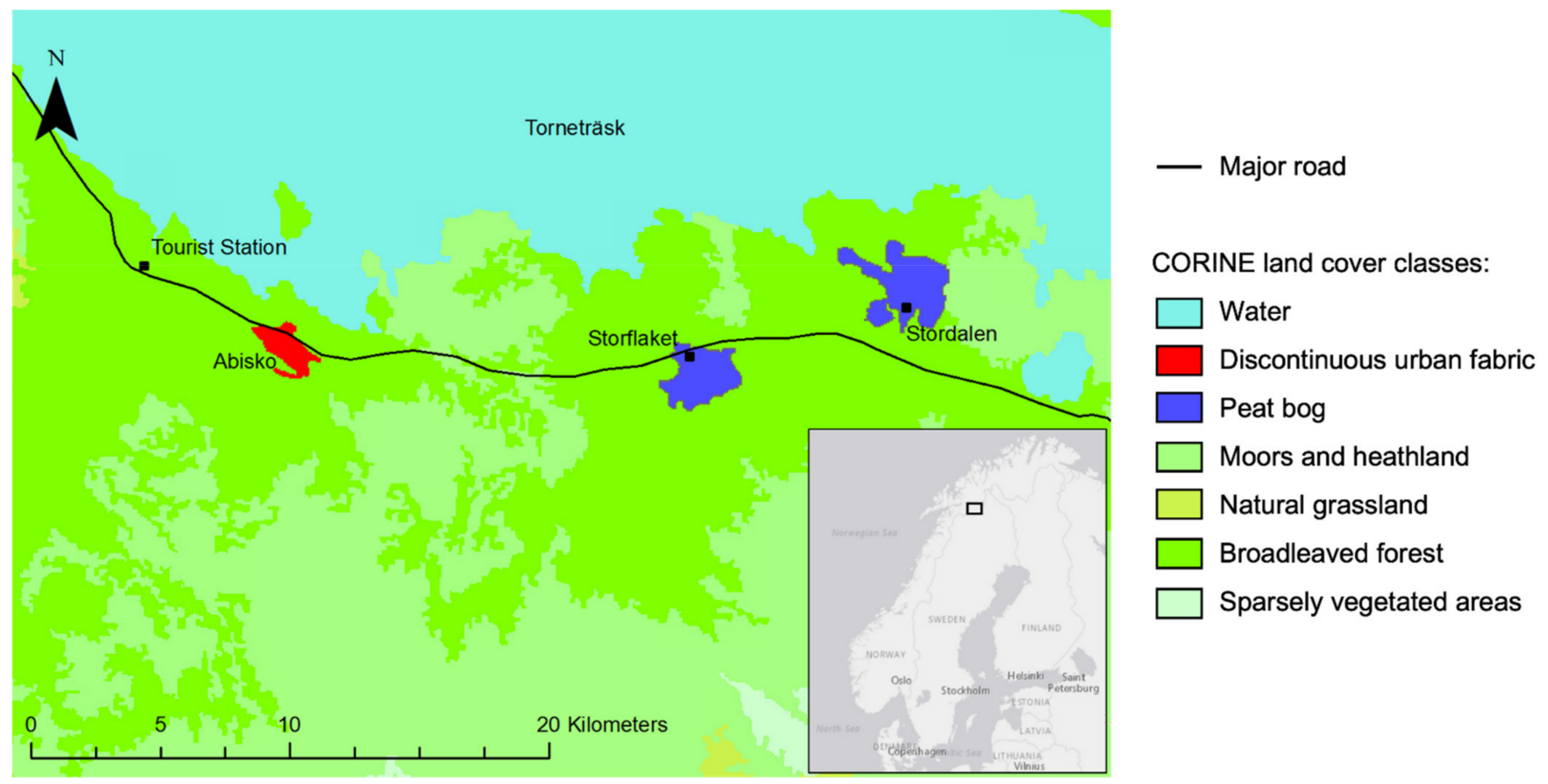

Figure 1. Map showing the location of the three permafrost peatland study sites: Tourist Station, Storflaket, and Stordalen. Inset: Location of Abisko in northern Sweden. The landcover classes were based on the Corinne land cover classification.

The study sites comprise areas of raised palsas (i.e., relatively dry peat plateaus) and waterlogged areas with fen or birch forest vegetation. The vegetation on the palsa were composed of bryophytes (e.g., Sphagnum fuscum), lichens, and dwarf shrubs (Empetrum nigrum, Andromeda polyfolia, and Betula nana [14]). The most common herbaceous species was Rubus chamaemorus. All three sites have signs of permafrost thaw, indicated by a lowering of the ground surface, greater soil moisture levels, and areas of palsa collapse (Figure 2). Recently collapsed areas adjacent to and within the plateau areas tended to be vegetated by Sphagnum sp. and Eriphorum vaginatum and E. angustifolium. Extensive collapsed and subsequently flooded areas tended to be vegetated by graminoids, mainly Carex and Eriophorum species, and deciduous shrubs, such as Salix lanata, S. myrsinites, and Betula nana. Forested wetland areas tended to be located adjacent to streams and at the perimeters of the wetland areas. The mean peat depth was ca 60, 94, 50, and $40 \mathrm{~cm}$, in areas that contained palsas, Sphagnum sp., sedge, and forested wetland areas, respectively; mean 
soil C storage in the top $100 \mathrm{~cm}$ was 52, 34, 33, and $40 \mathrm{~kg} \mathrm{SOC} \mathrm{m}^{-2}$ for palsa, Sphagnum sp., sedge, and forested wetland, respectively [44].

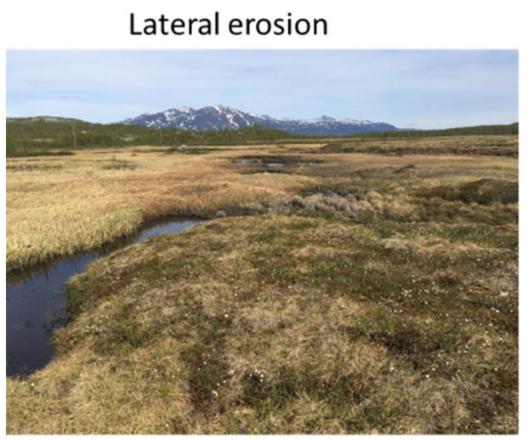

Internal palsa degradation

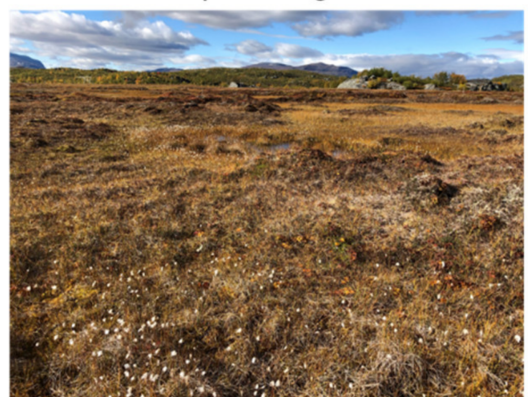

Extensive fen

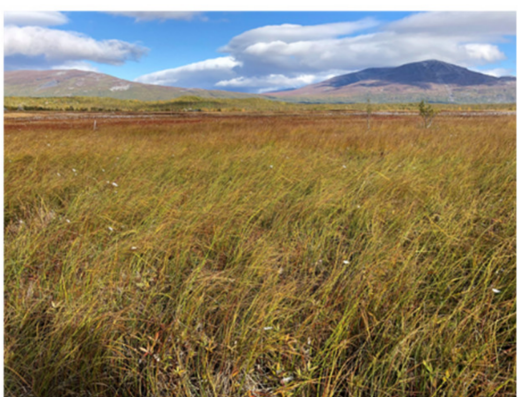

Figure 2. Photos showing impacts of permafrost thaw on the mires.

The temperature and snow conditions varied substantially between years within the study period (Figure S1 [45]). The winter of 2019-2020 was substantially milder than the preceding winters; at the $20 \mathrm{~cm}$ depth, temperature did not deviate much from $0{ }^{\circ} \mathrm{C}$. Summer temperatures were also variable between years, with very high July temperatures being recorded during 2018. Snow depth also varied considerably between years, with the lowest snow depth in the 2017-2018 winter.

\section{Methods}

\subsection{Field Data Collection on Vegetation and Soil}

The properties of common vegetation types were collected from the three study sites at the time of maximum active layer depth (end of September/beginning of October) in 2020. Specifically, we determined the active layer depth, vegetation type, vegetation height, soil moisture, and soil temperature in the field. Data were collected across 396 locations (in total for the three study sites) having a $3 \times 3 \mathrm{~m}$ area of homogenous vegetation (all plots were georeferenced using a differential GPS (dGPS; Trimble R8s; vertical error of $1.5 \mathrm{~cm}$ ). The vegetation types were based on those used in Siewert (2018), with some modifications to reflect the vegetation classes specific to the palsa mire study sites. The vegetation classes were dry lichen and low evergreen dwarf shrub (subsequently denoted 'dry lichen'), 'dwarf shrub', 'moist moss' with Sphagnum fuscum and R. Chamemoursus (these three classes are found on the raised palsa areas), 'Sphagnum wetland', Carex-Eriophorum wetland (subsequently denoted 'sedge wetland'), 'willow wetland', and 'forested wetland' (Figure 3).

The active layer depth was measured using a graded metal probe, and where the active layer depth was greater than $140 \mathrm{~cm}$, these were recorded as $>140 \mathrm{~cm}$. When mineral soils or rock were hit before the active layer was reached, no active layer recording was taken and instead the depth of the peat layer was recorded. It is possible that permafrost occurred at greater depths than $140 \mathrm{~cm}$; however, core sampling in Sphagnum, sedge, and forested wetland vegetation at Stordalen indicate no permafrost at greater depth in these vegetation types [44]. Volumetric soil moisture was measured using a Theta probe and Theta meter (DeltaT devices; Cambridge, UK), soil temperature was measured at $5 \mathrm{~cm}$ depth using a digital thermometer, and the height of the vegetation was determined using a tape measure (in the forested wetland, the canopy height measured was that of the understory vegetation (mainly sedges and willow)). 

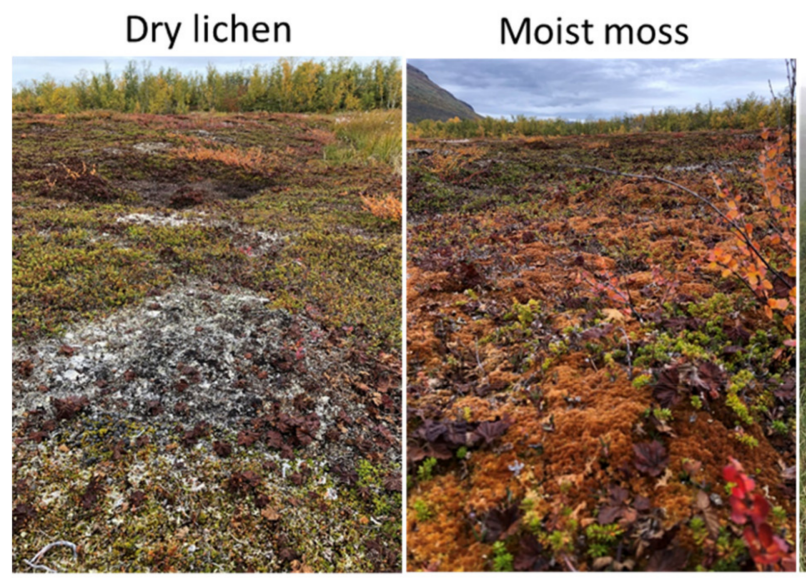

Dwarf shrub
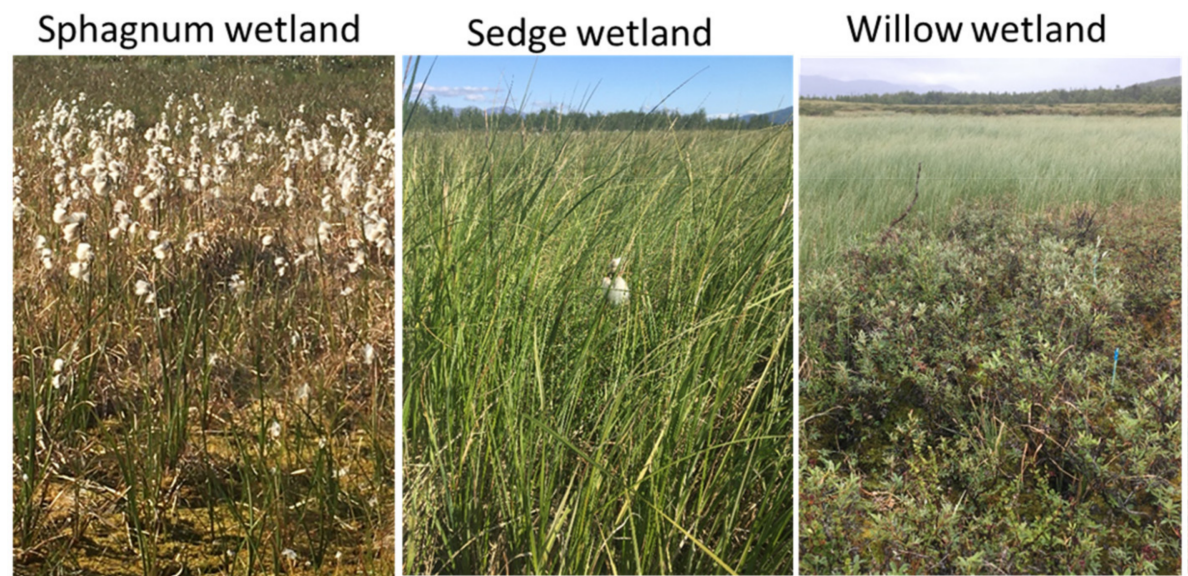

Forested wetland

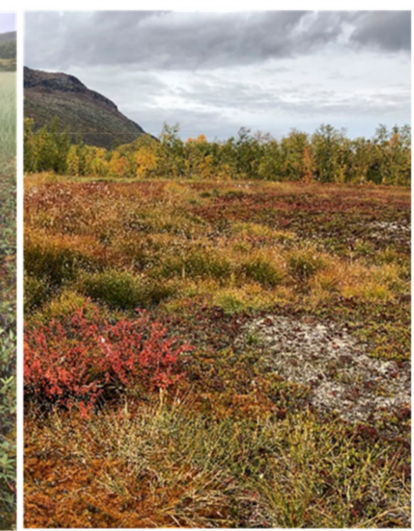

Figure 3. Photos of the dominant vegetation types found at the study sites. Upper row: Raised palsa vegetation found in locations with shallow active. Lower row: Fen vegetation found in locations with no permafrost.

\subsection{Decadal Scale Permafrost Degradation and Palsa Contraction}

To determine historical rates of change of palsa size at the three study sites, we obtained orthophotos captured by occupied airborne surveys from 1960, 2002, 2008, and 2018 from the Swedish Survey dataset (the orthophotos were $5 \mathrm{~km} \times 5 \mathrm{~km}$, the resolution for the 1960 and 2002 photos were $1 \mathrm{~m}$, and for 2008 and 2018 the resolution was $0.5 \mathrm{~m}$ ). Within each of the orthophotos, we delineated the visible boundaries of palsas by digitising (using ArcGIS (ESRI)). Specifically, one interpreter delineated all palsas using the orthophotos for each study site. In areas where the palsa boundary was not clear, these sections were not used. As a quality control, two additional independent interpreters also delineated the palsas. In cases where the delineations made by the three interpreters varied by $>1 \mathrm{~m}$, these were excluded from the subsequent analysis. To analyse palsa shrinkage rates and/or collapse, 50 random $20 \mathrm{~m}$ long transects were drawn perpendicular to the palsa edge defined by the original interpreter. Along each transect, the distance between palsa delineations for different years were measured. Finally, rates of change were calculated for the different periods of 1960-2002, 2002-2008, 2008-2018, and over the entire period 1960-2018.

\subsection{UAV-Captured Data for Digital Elevation Models (DEMs) and Vegetation Mapping}

Multispectral and true colour RGB data were captured across Storflaket and Stordalen in 2017 and 2020, and data from the Tourist St. site was collected in 2021 using a fixed-wing Unoccupied Aerial Vehicle (UAV; Sensefly Ebee; Table S1). Multispectral and true colour imagery were collected during sequential flights. For the multispectral data collection, the UAV was fitted with a Parrot Sequoia multispectral sensor which obtains spectral 
measurements across four bands: Green $(550 \mathrm{~nm} \pm 40 \mathrm{~nm}), \operatorname{Red}(660 \mathrm{~nm} \pm 40 \mathrm{~nm})$, Red Edge $(735 \mathrm{~nm} \pm 10 \mathrm{~nm})$, and Near Infrared $(790 \mathrm{~nm} \pm 40 \mathrm{~nm})$, with an average density of $2.56 \mathrm{~m}^{3}$. The UAV was flown at a height of $106 \mathrm{~m}$ and obtained a total of 1353, 1624, and 1933 images across areas of approximately 64 ha, 54 ha, and 18 ha at Stordalen, Storflaket, and the Tourist Station, respectively. The true colour RGB imagery was collected with Sony WX and Canon G9X cameras at an elevation of $98 \mathrm{~m}$, resulting in a ground resolution of $\sim 2-3 \mathrm{~cm}$ after processing. The images were processed using Pix4D (Berlin, Germany) to produce an orthomosaic for each spectral band and a Digital Elevation Model (DEM) for each site, using a UTM $34 \mathrm{~N}$ coordinate system. The resulting spatial resolutions of both outputs across all three sites varied between 0.08 and $0.11 \mathrm{~m} / \mathrm{px}$ for the multispectral data and between 0.02 and $0.03 \mathrm{~m} / \mathrm{px}$ for the RGB imagery.

To ensure the orthomosaic and DEM were accurately geolocated, we collected 48 ground control points using the dGPS across all three sites. Ground controls were collected from stable surfaces such as rock outcrops and anthropogenic structures in areas that were clearly identifiable in the images. The difference in ground elevation was calculated by subtracting the DEM in 2017 from 2020. Thus, a negative value represents a decrease in elevation over time-an indication of ground subsidence. The error associated with this change in elevation was calculated as the standard deviation of elevation change at all GCPs.

The multispectral UAV data were classified to output a vegetation cover map for the three study sites; for Stordalen and Storflaket the data from 2020 was used, and for the Toursit St. site, data from 2021 was used. A Support Vector Machine classification approach was used with ground data sampled randomly in June 2021 for Storflaket $(n=258)$ and Stordalen $(n=395)$ sites and in August 2021 for the Tourist Station (657). The ground points from each site were randomly split into training and validation datasets with proportions of $70 \%$ and $30 \%$. The UAV data was resampled to $0.5 \mathrm{~m}$ spatial resolution for the classification process. The three types of vegetation found on the raised palsa areas ('dry lichen', 'dwarf shrub, 'moist moss') were combined to a single class 'raised palsa', as the classifier could not distinguish between these vegetation types individually. A Shadow class was added to reduce confusion with water bodies e.g., within forested areas.

\subsection{Surface Motion from Sentinel-1 InSAR}

We used C-band SAR data freely available from the Sentinel-1 satellites (European Union's Copernicus Programme) to map multi-annual average velocity, subsequently denoted surface motion of the study areas. Interferometric Wide Swath mode images were gathered from 2017 to 2020, to coincide with those of the UAV-derived DEMs, and focussed on the thaw season between April and October for three separate years. A total of 125 images were acquired from the descending mode, and surface motion was obtained using the APSIS method (formally known as ISBAS), which relaxes the requirement for consistent phase stability for all observations using a coherence threshold of 0.45 . With improved coherence, compared to the SBAS-InSAR method, which struggles to work outside urban areas, APSIS has near-complete spatial and temporal coverage over natural vegetated surfaces, including peatlands [41,42,46-49].

InSAR processing required single-look complex images to be co-registered and multilooked. The multi-looking was by a factor of 2 in azimuth and 7 in range to generate a ground resolution of $20 \mathrm{~m} \times 20 \mathrm{~m}$. A total of 1892 interferograms were produced with a perpendicular baseline of $250 \mathrm{~m}$ and a maximum temporal baseline of 183 days to minimise phase ambiguities and maintain coherence. Use of long temporal baselines were necessary to capture more subtle trends of surface deformation. Good phase measurements have been shown to be possible using long temporal baselines over permafrost regions to monitor motion in the summer period, allowing for season-to-season pairs over numerous years [50]. Using a stable reference point located in the centre of Abisko village, first the multi-annual average velocity (or average surface displacement) between 2017 and 2020 (with more negative values representing subsidence) was calculated and, second, for each season, 
a time series of surface motion was produced, showing the change in relative height of the surface. Surface motion range for the 2017 and 2020 thaw periods were calculated by subtracting the minimum surface motion value from the maximum surface motion value within respective time series between June and October. These dates corresponded with documented surface temperatures for Abisko over the time period; June marked the full onset of surface thawing, whilst October marked the onset of freezing. Given that all three sites are located at a similar latitude, the onset of thaw and freeze were assumed to happen concurrently.

\subsection{Statistical Analysis}

We used residual maximum likelihood (REML) to test for significant differences between canopy height and active layer depth with vegetation; we used vegetation type as the fixed effect and site as the random effect. REML was also used to determine differences in the rate of palsa shrinkage among time periods and sites; we used time period and site as fixed effects and transect as the random effect. Two types of evaluations of the InSAR data in relation to vegetation type were carried out. First, all data were included to test for significant differences between vegetation types using REML, with site as the random effect. Second, the dataset was restricted to include only subsiding pixels (surface level change $<0$ ); differences between vegetation types within this subsection of the dataset was also analysed using REML, with site as the random effect. Standard error of differences were used to identify differences between vegetation types and sites.

\section{Results}

\subsection{Vegetation and Soil Field Data}

Among the seven vegetation classes across the study sites, canopy height was lowest for dry lichen and moist moss; dwarf shrub and Sphagnum wetland vegetation had intermediate canopy heights; while the tallest vegetation types were the sedge wetland, willow wetland, and forested wetland (understory canopy height) classes (Table 1). Soil moisture content was lowest in the dry lichen, moist moss, and dwarf shrub vegetation types, while for the other vegetation types, moisture levels were very high or saturated (Table 1). Soil temperatures (measured in September) were somewhat lower in the two drier vegetation types (Table 1). Mineral soil was reached before the permafrost in 33, 19, and 17\% of the measurement points at the Tourist St., Storflaket, and Stordalen sites, respectively. This was most common in the willow and forested wetland vegetation types.

Table 1. Properties of the different vegetation types (mean and SE are shown).

\begin{tabular}{ccccccc}
\hline Vegetation Type & \multicolumn{2}{c}{$\begin{array}{c}\text { Canopy Height } \\
(\mathbf{c m})\end{array}$} & \multicolumn{2}{c}{ Soil Moisture (\%) } & \multicolumn{2}{c}{ Soil Temperature $\left({ }^{\circ} \mathbf{C}\right)$} \\
\hline Dry lichen & 4.3 & $(1.0)$ & 38.9 & $(2.1)$ & 3.5 & $(0.11)$ \\
Moist moss & 7.8 & $(0.7)$ & 40.9 & $(1.5)$ & 3.5 & $(0.08)$ \\
Dwarf shrub & 36.7 & $(4.0)$ & 46.6 & $(5.3)$ & 4.5 & $(0.2)$ \\
Sphagnum wetland & 24.9 & $(1.5)$ & 98.3 & $(0.8)$ & 4.3 & $(0.1)$ \\
Sedge wetland & 46.8 & $(1.8)$ & 100 & $(0)$ & 4.7 & $(0.1)$ \\
Willow wetland & 74.1 & $(7.4)$ & 89.5 & $(4.9)$ & 4.2 & $(0.3)$ \\
Forested wetland & 47.4 & $(7.0)$ & 70.4 & $(6.9)$ & 4.7 & $(0.2)$ \\
\hline
\end{tabular}

The active layer depth was shallowest in dry lichen and moist moss vegetation, with the most common active layer depth in this vegetation type being in the range of 50-69 $\mathrm{cm}$ (Figure 4a). For the dwarf shrub vegetation, the most common active layer depth was $>140 \mathrm{~cm}$ (Figure 4a). For all the wet vegetation classes, the most common active layer depth was $>140 \mathrm{~cm}$, although the Sphagnum and sedge wetland vegetation types had some shallower depths in areas adjacent to intact palsa areas (Figure $4 \mathrm{~b}$ ). 

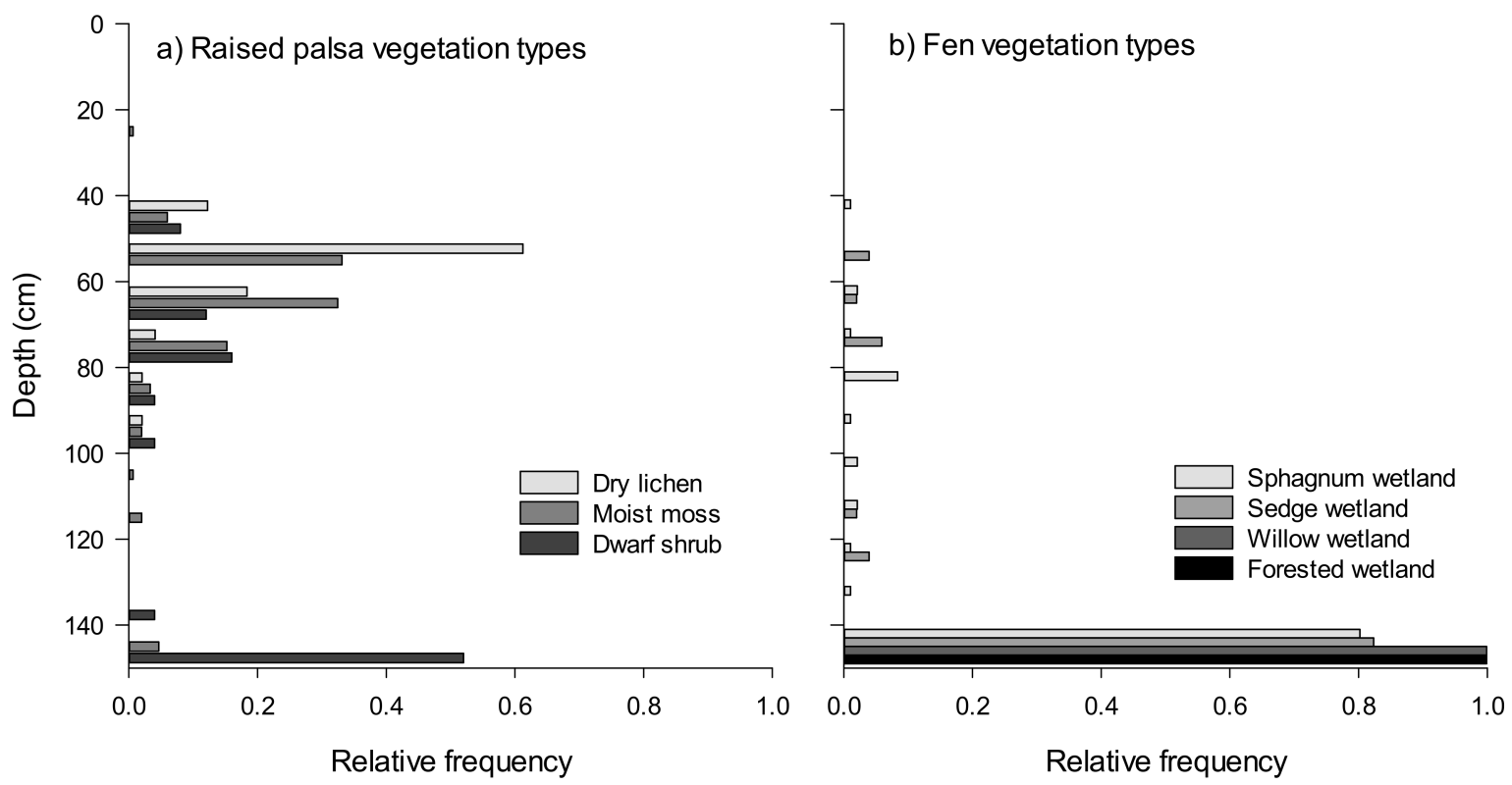

Figure 4. Relative frequency of active layer depth for common vegetation types associated with (a) drier and (b) wetter soil conditions at the three study sites.

\subsection{Decadal Scale Permafrost Degradation and Palsa Contraction}

The historical orthophotos showed evidence of permafrost thaw at all three study sites because the edges of the palsas were contracting in their areal extent over time (Figure 5a). The contraction of the palsas was greatest at the Storflaket and Tourist station mires at $9.3 \pm 0.27$ and $9.0 \pm 0.56 \mathrm{~m}$ over the entire study period (1960-2018); contraction rates at Stordalen were $3.1 \pm 0.18 \mathrm{~m}$ for the same time period (Figure $5 \mathrm{~b}$ ). The time series analysis showed that rates of contraction were not linear over time. Rates were lowest between 1960 and $2002\left(0.12 \pm 0.006 ; 0.13 \pm 0.005 ; 0.03 \pm 0.002 \mathrm{~m} \mathrm{year}^{-1}\right.$, at the Tourist St., Storflaket, and Stordalen sites, respectively) and highest between 2002 and 2008 at all three sites $\left(0.32 \pm 0.04 ; 0.21 \pm 0.013 ; 0.18 \pm 0.012 \mathrm{~m}\right.$ year $^{-1}$ at the Tourist St., Storflaket, and Stordalen sites, respectively) (Time period: $\mathrm{F}_{2812}=89.53 ; p<0.001, \mathrm{SED}=0.025$ ). The largest rates of loss were at the Tourist St. site over the 2002-2008 period (Site $\times$ Time period interaction: $\left.\mathrm{F}_{4812}=17.97, p<0.0014\right)$.

\subsection{UAV-Derived Mapping of Vegetation Types}

Across the region of interest, the wetlands were composed of a fine scale mosaic of vegetation types (Figure 6a). The raised palsa vegetation type covered the largest area within the mapped wetland areas at the Stordalen and Storflaket sites, while forested wetland was the most common class at the Tourist station mire (Figure 6, Table 2). At the edges of palsas, where the peat contained deep cracks, B. nana typically was taller $(50-100 \mathrm{~cm})$ and the ground became waterlogged. In subsiding palsa areas covered with dry lichen and moist moss vegetation, vascular plants showed signs of anoxia resulting from the flooding, and S. fuscum out-competed the lower statue vascular plants. Surrounding the palsa areas were various fen vegetation types (Table 2, Figure 6). Extensive areas of Sphagnum wetland were found adjacent to the thawed edges of palsas and also in subsided areas within the palsas. Sedge wetlands formed extensive communities in areas with deeper water levels and transitioned into willow wetland. Forested wetland areas were mainly found along streams, lake edges, and the outer edges of the mires. The overall accuracy of classification for the Tourist St., Storflaket, and Stordalen sites was 82, 74, and $70 \%$, respectively (confusion matrices are shown in Tables S1-S3). 


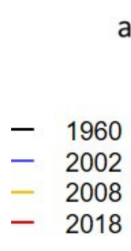

\section{(1)}
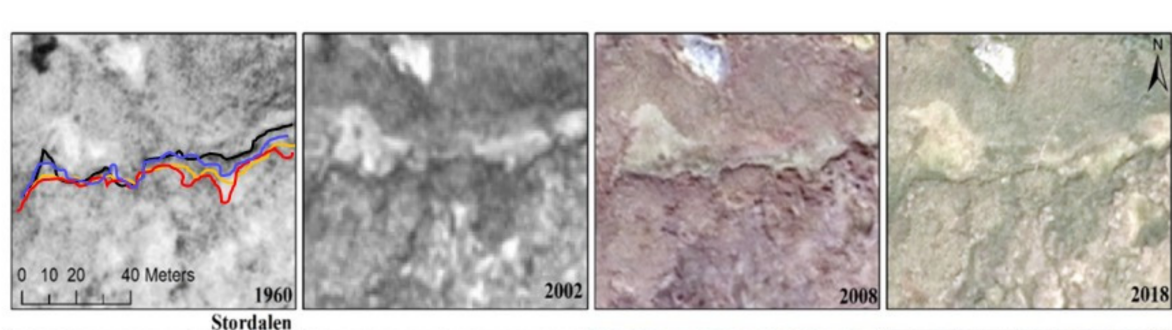

b)
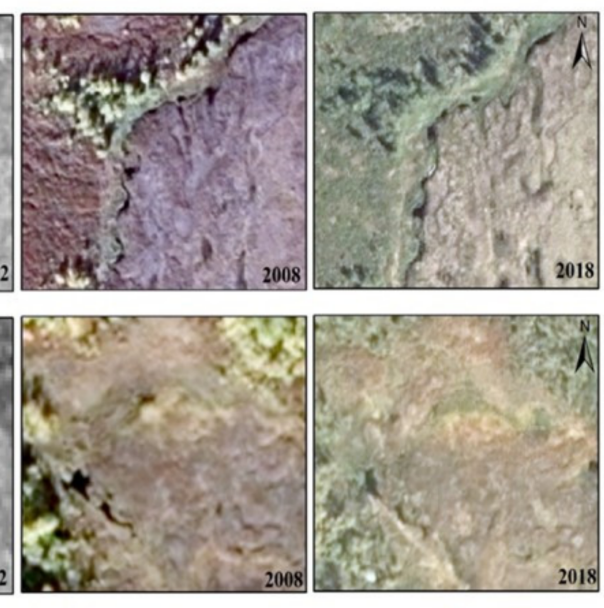

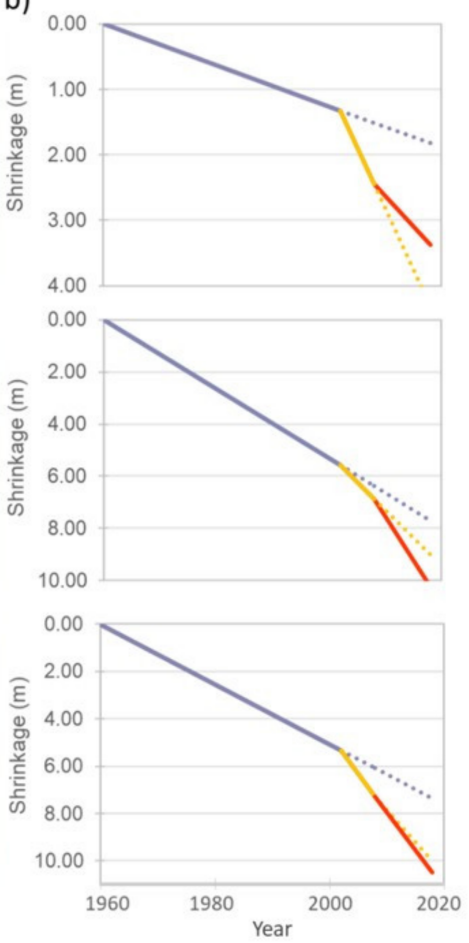

Figure 5. (a) Orthophotos of palsa edges taken in 1960, 2002, 2008, and 2018 for the Tourist St., Storflaket, and Stordalen sites. The lines represent contraction over time at each site. At the Tourist St. site, only lines for 1960 and 2002 are added because, after that, the palsa in this location is too degraded to define the edge along this section of the mire. Note that the scale differs between the sites, reflecting the differences in size of the study areas. (b) Contraction of palsa edges over time at the three study sites.

\subsection{Subsidence Determined from UAV Derived DEMs}

The UAV-derived DEMs from the sites clearly show the distribution of the raised palsa plateaus surrounded by lower-lying fen areas (Figure 7a). The greatest elevation difference between raised palsa areas and surrounding fen vegetation was at the Stordalen site, where the highest areas were ca $386 \mathrm{~m}$ above sea level (absl), and the fens were ca. $382 \mathrm{~m}$ absl. Both Stordalen and Storflaket contained extensive raised plateau areas, while the elevation of the palsa relative to the surrounding fen vegetation was lowest at the Tourist Station mire (Figure $7 b$ ). Locations experiencing permafrost thaw and deepening of active layers is evident in Figure 5a as areas of lower elevation within the raised plateaus at each site. The dGPS data showed significant differences in altitude betwen the vegetation types (Figure $7 \mathrm{~b}$ ). The raised palsa had the highest altitude, followed by Sphagnum wetland. The altitude difference between raised palsa and Sphagnum wetland was between 0.4 and $0.7 \mathrm{~m}$ at the three sites, while the difference between Sphagnum vegetation and sedge wetland ranged between 0.1 and $0.6 \mathrm{~m}$ at the three sites.

The ground motion estimated from the UAV derived differential DEM between July 2017 and Aug 2020 showed a high degree of surface dynamic over the study period (Figure 8). High levels of subsidence $(-25 \mathrm{~cm})$ were detected around the edges of the raised palsa plateaus, thus indicating evidence of lateral erosion. A lower level of subsidence was also apparent across large areas of the interior parts of the palsa areas. Areas of uplift are indicated in the lower-lying fen areas adjacent to the palsa; this is most likely reflecting the later growth stage (i.e., taller) of the sedge vegetation in 2020. 
a)
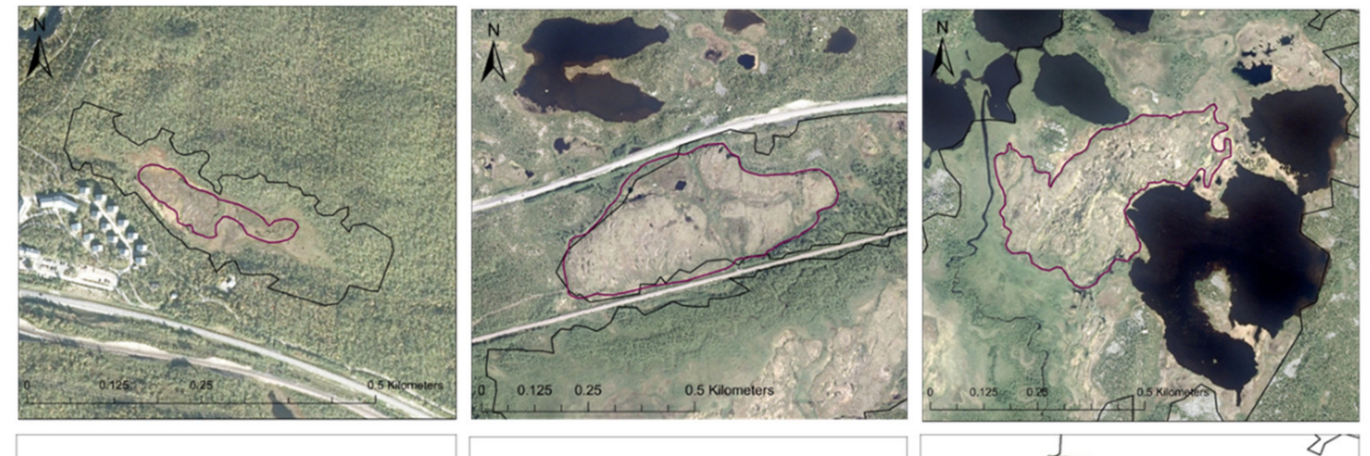

Orthophoto 2018

- Focus palsa-fen area

- Wetland area

b)
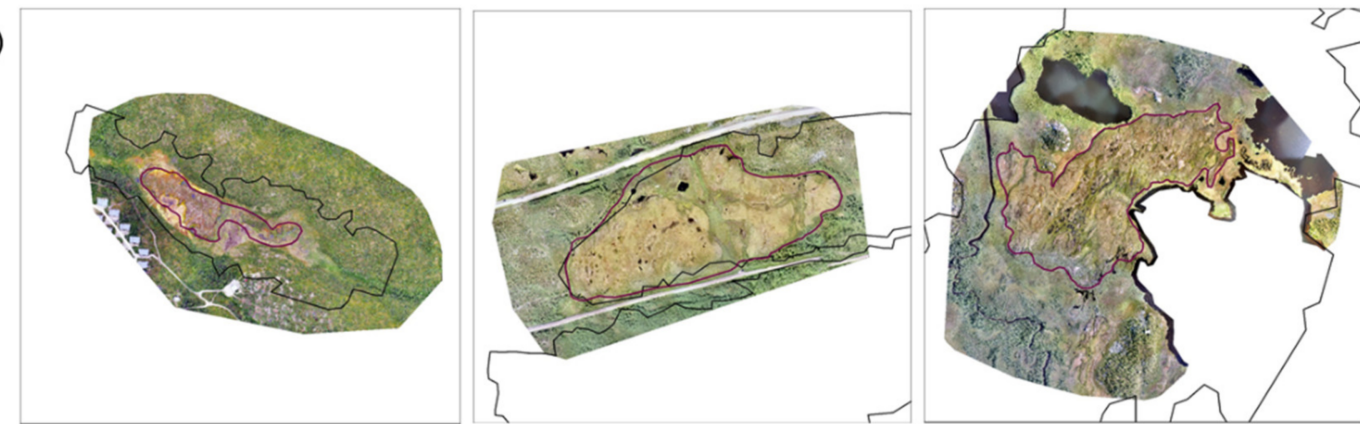

c)
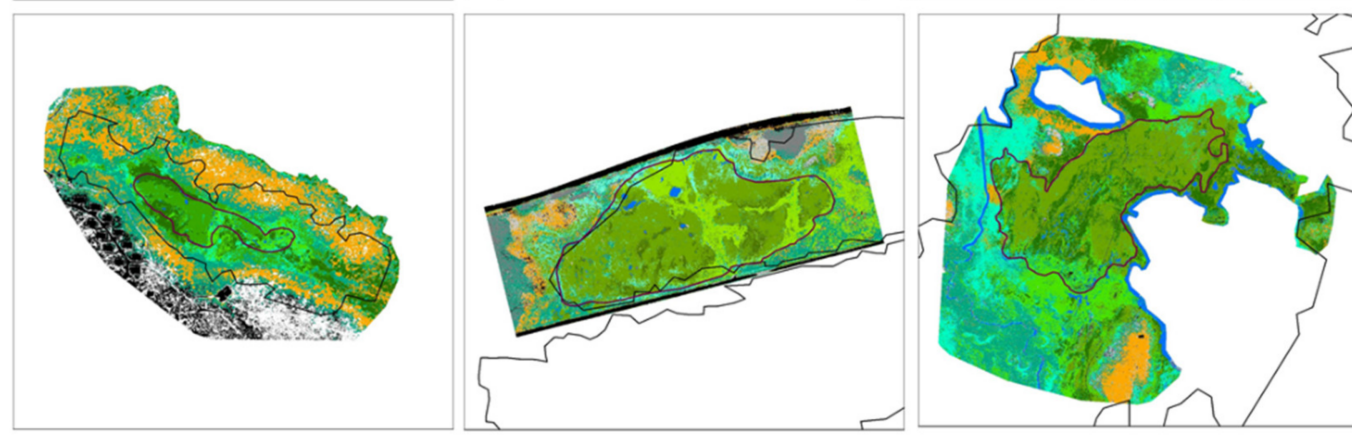

Vegetation classification

Figure 6. (a) Orthophoto imagery from 2018, (b) UAV RGB imagery, and (c) detailed vegetation maps within the wetland areas at the three study sites of interest: Tourist St., Storflaket, and Stordalen, respectively. Associated confusion matrices are in Tables S1-S3. Of the overall wetland areas delineated in the maps, a focus palsa-fen study area, also indicated in the map, was subsequently used for the digital elevation models.

Table 2. Area of different wetland vegetation types at each of the three study sites and their proportional contribution to land cover at the sites.

\begin{tabular}{ccccccc}
\hline \multirow{2}{*}{ Vegetation Type } & \multicolumn{2}{c}{ Tourist St. } & \multicolumn{2}{c}{ Storflaket } & \multicolumn{2}{c}{ Stordalen } \\
\cline { 2 - 7 } & Area (ha) & $\begin{array}{c}\text { Proportion of } \\
\text { Wetland Area (\%) }\end{array}$ & Area (ha) & $\begin{array}{c}\text { Proportion of } \\
\text { Wetland Area (\%) }\end{array}$ & $\begin{array}{c}\text { Area (ha) } \\
\text { Proportion of } \\
\text { Wetland Area (\%) }\end{array}$ \\
\hline Raised palsa & 1.0 & 18 & 8.2 & 44 & 10.1 & 24 \\
Sphagnum wetland & 0.7 & 14 & 1.5 & 8 & 6.0 & 14 \\
Sedge wetland & 0.4 & 7 & 4.2 & 7 & 6.1 & 14 \\
Willow wetland & 0.4 & 8 & 1.3 & 10 & 6.1 & 16 \\
Forested wetland & 1.4 & 25 & 1.9 & 7.0 & 14 \\
\hline
\end{tabular}


a)

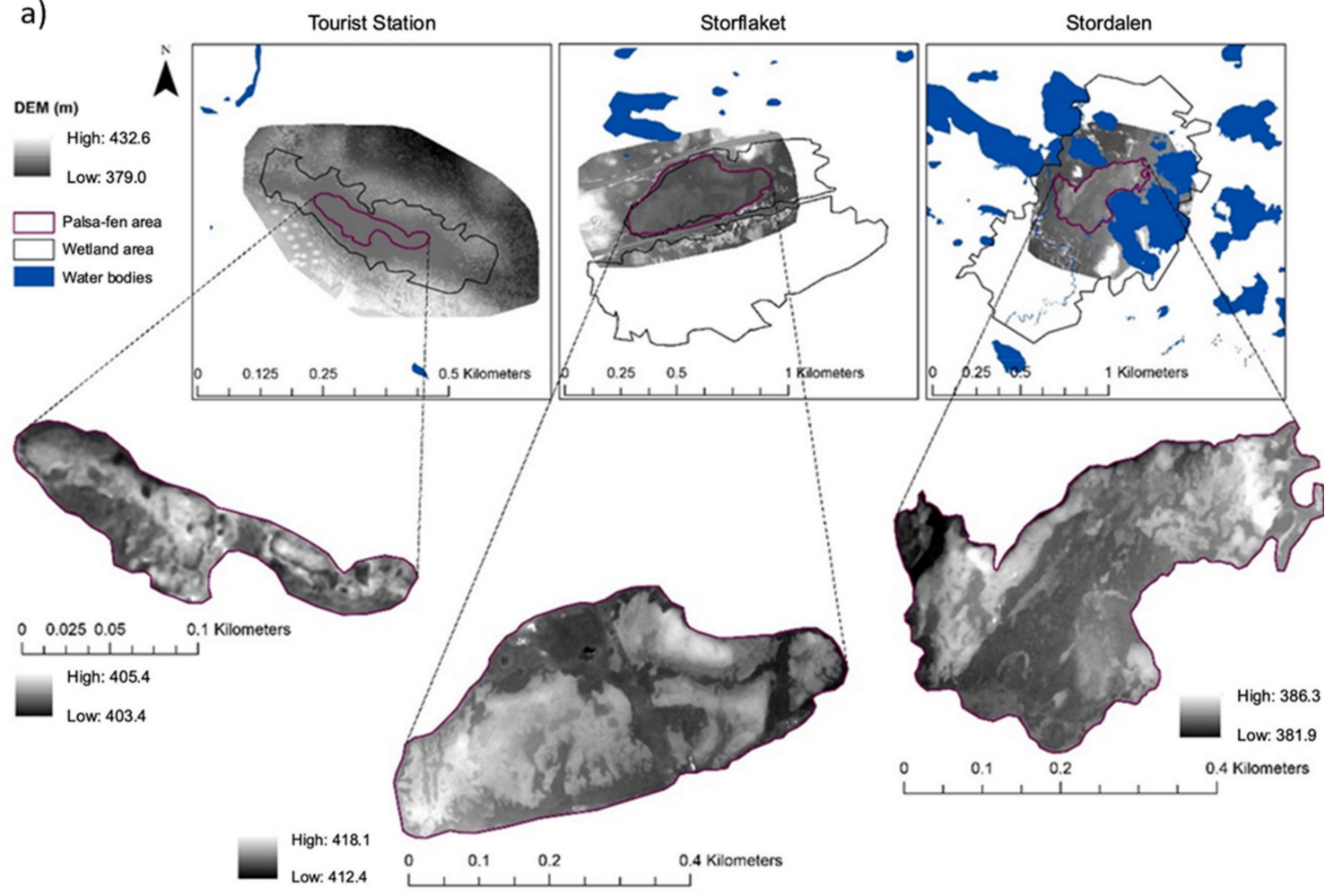

b)
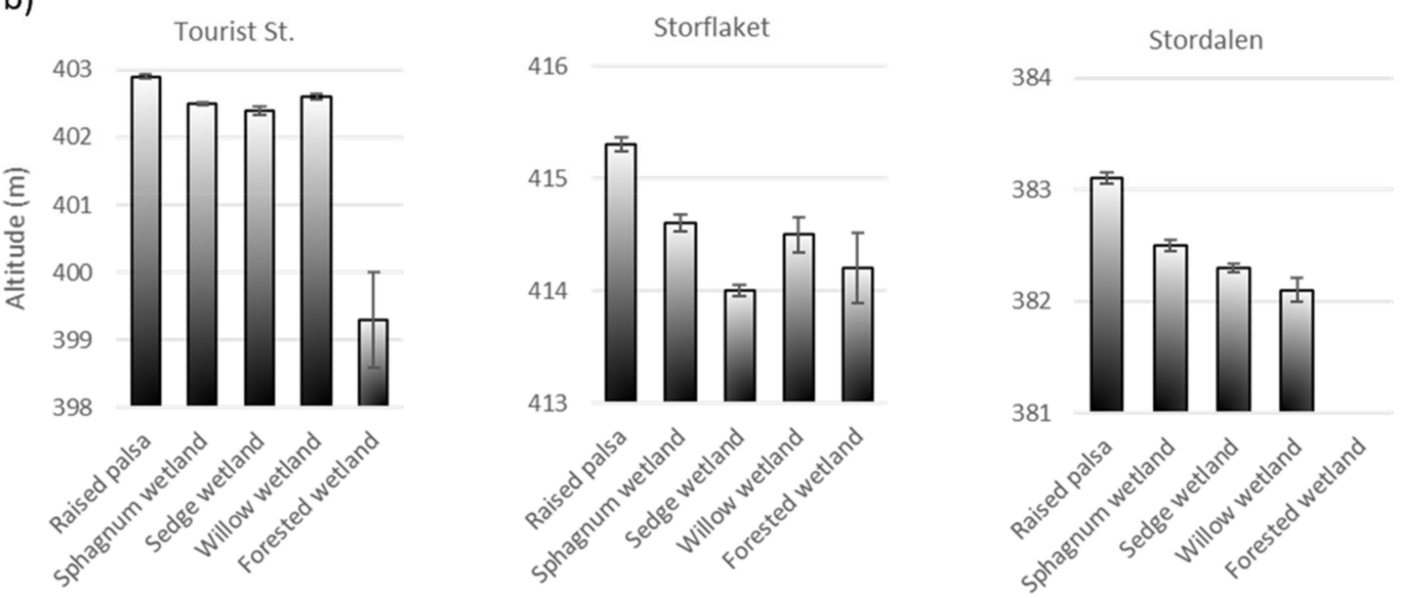

Figure 7. (a) Digital Elevation Models derived from UAV data showing the wetland areas and water bodies for the three study sites: Tourist St., Storflaket, and Stordalen. The cut-outs are zoom-ins of areas showing a mixture of raised palsa and lower lying fen areas. Note that the grey scale denoting the height differences differs between the 'wetland' and 'zoomed-in' figures, as does the spatial scale. (b) Surface position (altitude) of different vegetation types measured using a high precision dGPS at ca. 500 points overall in September 2020 at the three sites. Mean and SE are shown.

\subsection{Surface Motion as Determined from Sentinel-1 ASPIS-InSAR}

ASPIS-InSAR outputs showed good coherence overall, with a high number of coherent interferometric pairs out of a total of 1892 achieving optimal coherence over all wetland sites (average coherence; Tourist St., 1583; Storflaket, 1571; Stordalen, 1557). An overall low standard error was also exhibited across all wetland sites (average SE: Tourist St., $0.162 \mathrm{~cm}$; Storflaket, $0.186 \mathrm{~cm}$; Stordalen, $0.187 \mathrm{~cm}$ ). 


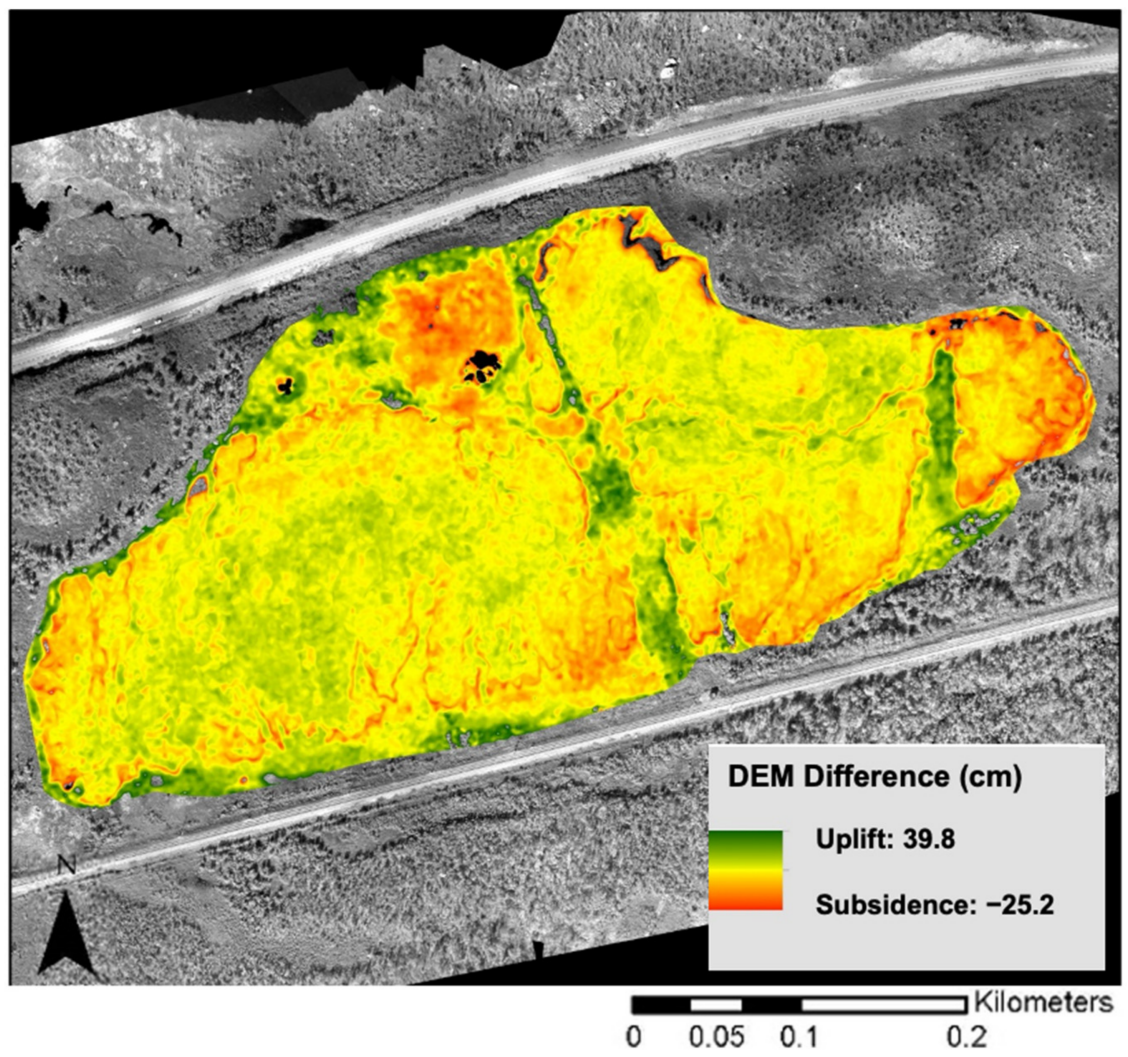

Figure 8. Surface motion for the Storflaket site determined from differential DEM generated from the UAV derived 2017 and 2020 DEMs. The overall error of the differential DEM is $\pm 0.12 \mathrm{~cm}$. Note that the areas of green "uplift" in parts of the fen areas surrounding the palsa is due to lack of penetration to the ground surface in densely vegetated areas where the ground was not visible, hence the "uplift" in these areas is likely linked to vegetation properties and should be interpreted with caution. On the more sparsely vegetated areas on the palsas, detection of the ground surface in the point cloud was good.

APSIS-InSAR surface motion mapped at $20 \mathrm{~m}$ resolution depicted areas of subsidence across all three study sites (Figure 9a), with the greatest subsidence rates of $1.5 \mathrm{~cm}$, between 2017 and 2020, found in Stordalen. At Stordalen, raised palsa vegetation had the greatest overall subsidence rates, while sedge wetland had the greatest subsidence rates at Storflaket and the Tourist St. sites (Table 3; Vegetation $\times$ Site: $\mathrm{F}=2.53 ; p<0.01, \mathrm{SED}=0.06 \mathrm{~cm}$ ); however, all wetland vegetation types showed subsidence overall. The lowest subsidence rates were for anthropogenic surfaces (not illustrated); these were generally stable, i.e., showed no or very limited signs of ground motion.

When the analysis was constrained to only subsiding pixels, there was an overall significant difference in subsidence rates (Vegetation: $\mathrm{F}=65.1, p<0.001, \mathrm{SED}=0.027 \mathrm{~cm}$ ), with the greatest subsidence rates found for raised palsa. The differences in subsidence among vegetation types were significant at Stordalen and Storflaket (Vegetation $\times$ Site: $\mathrm{F}=2.39, p<0.05, \mathrm{SED}=0.058 \mathrm{~cm}$ ); at Stordalen and Storflaket, raised palsa as well as raised palsa and sedge wetland, respectively, had the greatest subsidence rates, while at the Tourist St. site there were no significant differences between vegetation types. At Stordalen, the area of high subsidence rates in the areas to the north of the lake in the centre of the map corresponded to an extensive area of subsiding palsa (pers. obs., Sofie Sjögersten). The lack of significant differences between vegetation types at the Tourist St. may in part be linked to the smaller extent and consequent pixel count per vegetation type.

Summary statistics of the within-thaw-season variability in surface motion range were similar between the 2017 and 2020 datasets at the Tourist St. and the Storflaket sites, while the surface motion range was greater for 2020 at the Stordalen site across all vegetation 
types (Figure 9b,c, Table S4). At Stordalan, the area of greater surface motion range detected by the InSAR in 2020 (Figure 9c) spatially corresponded to some of the areas of greatest ground subsidence measured by the multi-annual average velocity (Figure 9a).

a)

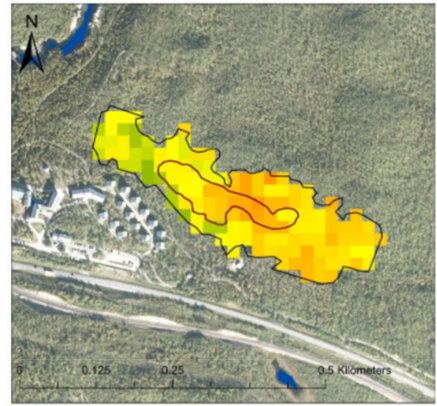

b)

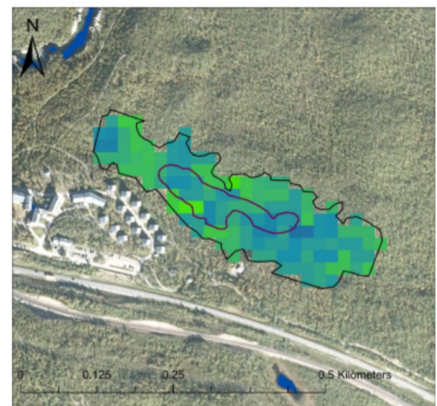

c)

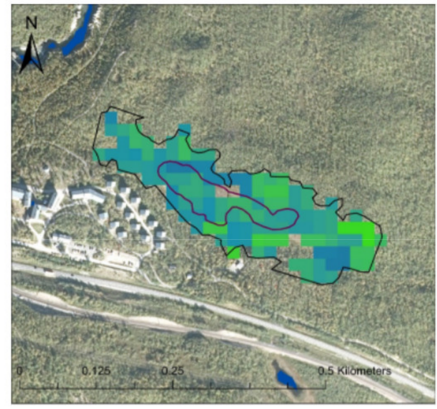

d)
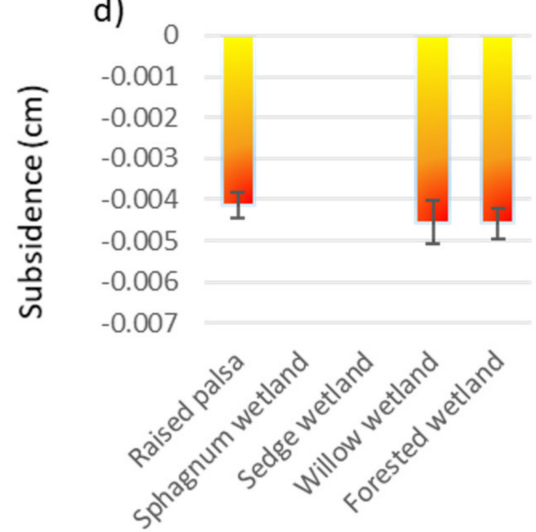
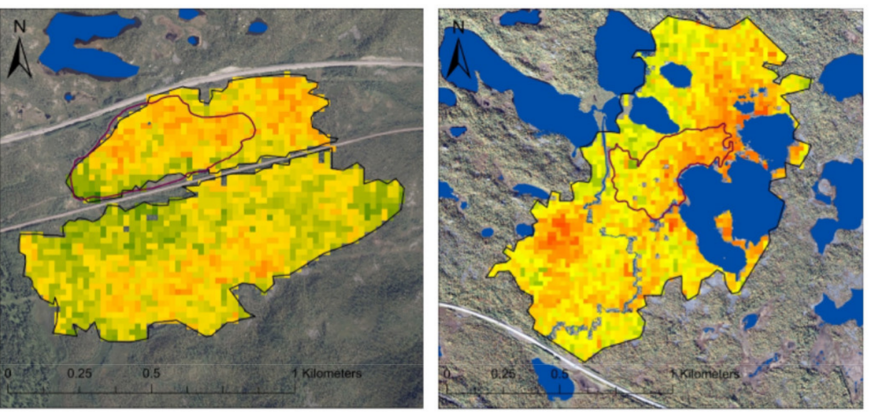

Average surface level change 2017 - 2020 (cm)
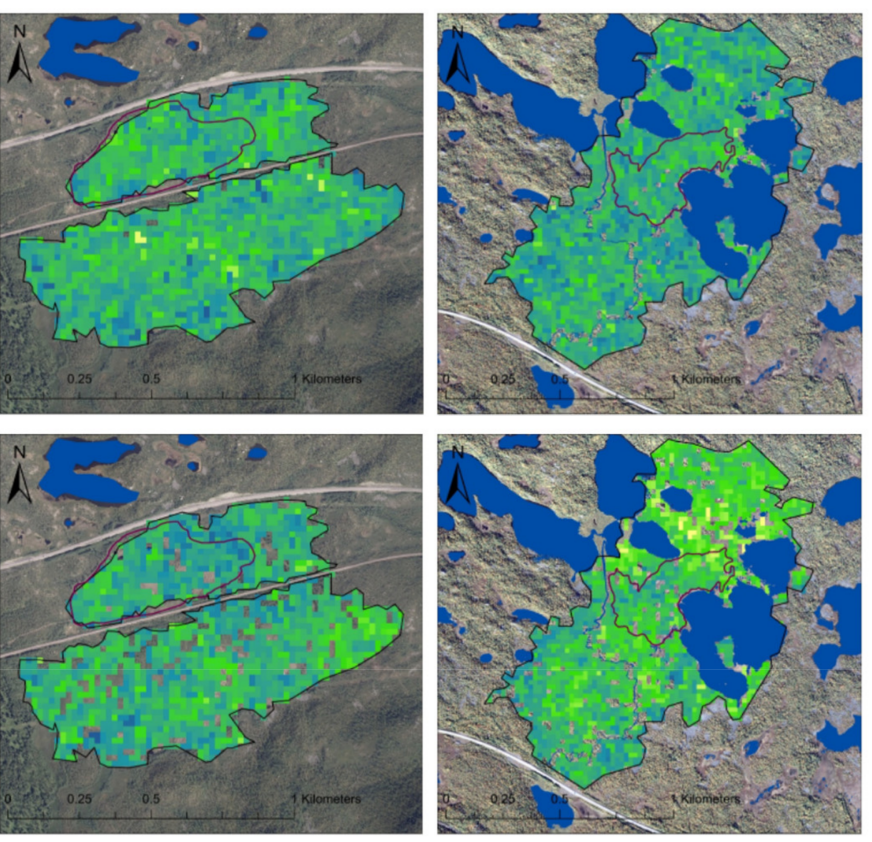

Surface level range within snow-free period $2020(\mathrm{~cm})$

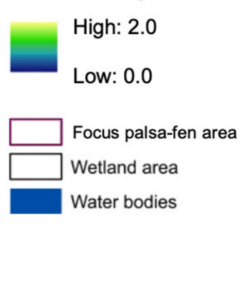

Surface level range within snow-free period $2017(\mathrm{~cm})$ High: 2.0 Low: 0.0

$\square$ Focus palsa-fen area
$\square$ Wetland area
Water bodies
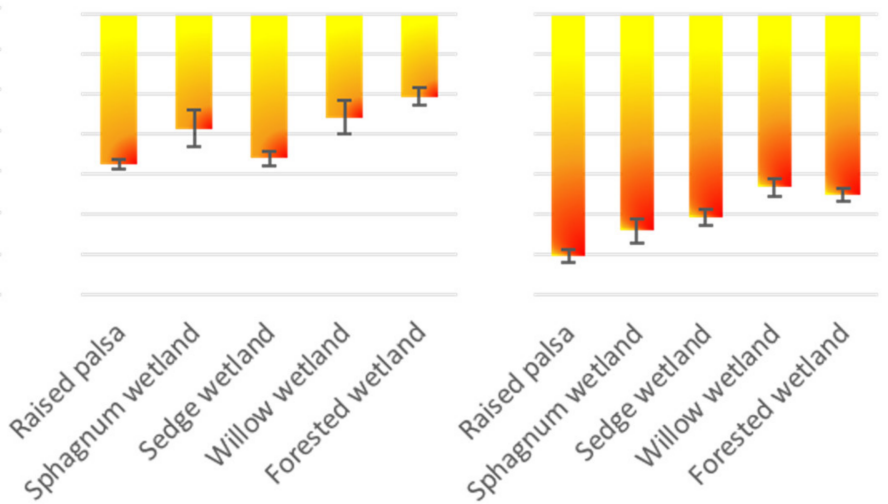

Figure 9. APSIS-InSAR derived surface motion (multi-annual average velocity) for the Tourist station, Storflaket, and Stordalen study sites. (a) Average surface motion between 2017 and 2020. (b) Surface motion range between April and October 2017. (c) Surface motion range between April and October 2020, (d) Rates of subsidence calculated from the surface motion velocity (cm between 2017 and 2020) among different vegetation classes in subsiding pixels; mean and SE are shown. A greater negative value indicates greater subsidence rates. 
Table 3. Surface motion (multi-annual average velocity) between 2017 and 2020 at the Tourist St., Storflaket, and Stordalen sites for the target vegetation classes. Mean and SE are shown. * Anthropogenic statistics have been calculated for areas outside the wetland to inform surface stability.

\begin{tabular}{ccccccc}
\hline & \multicolumn{2}{c}{ Tourist St. (cm) } & \multicolumn{2}{c}{ Storflaket $(\mathbf{c m})$} & \multicolumn{2}{c}{ Stordalen $(\mathbf{c m})$} \\
\hline Anthropogenic * & -0.1 & $(0.059)$ & -0.091 & $(0.026)$ & & \\
Raised palsa & -0.389 & $(0.05)$ & -0.255 & $(0.019)$ & -0.58 & $(0.018)$ \\
Sphagnum wetland & -0.351 & $(0.044)$ & -0.114 & $(0.073)$ & -0.498 & $(0.030)$ \\
Sedge wetland & -0.455 & $(0.053)$ & -0.331 & $(0.019)$ & -0.501 & $(0.021)$ \\
Willow wetland & & & -0.144 & $(0.052)$ & -0.385 & $(0.022)$ \\
Forested wetland & -0.263 & $(0.038)$ & -0.117 & $(0.032)$ & -0.431 & $(0.018)$ \\
\hline
\end{tabular}

\subsection{Comparing Surface Motions Derived from Differential DEMs and ASPIS-InSAR}

To investigate how the InSAR data reflects fine scale patterns, we compared the outputs of InSAR- and UAV-derived differences in elevation across three areas at the Storflaket site. The range of motion was lower in the InSAR compared to that estimated by the differential UAV data (Figure 10). The maximum subsidence reported in Figure $9 \mathrm{a}$ is $-1.5 \mathrm{~cm}$, while the maximum subsidence in Figure 10c is $-25 \mathrm{~cm}$ over the same time period, showing that the differences in spatial units have a large influence on the reported subsidence rates. The vertical standard error of the InSAR data showed lower variation in the more intact interior parts of the raised palsa (Figure 9b), which are further from the collapsing edges of the palsas, compared to the edges of palsa or areas of fen vegetation surrounding the palsas (Figures 6 and 7).

a) InSAR derived surface motion

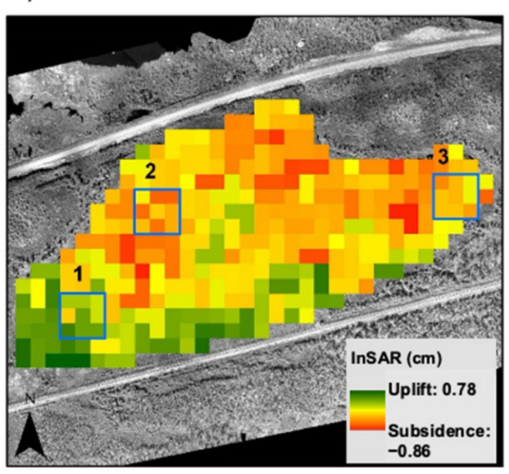

b) InSAR vertical standard error

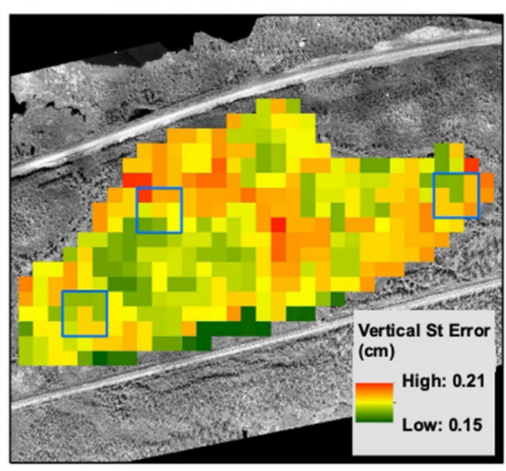

c) Surface motion from differential DEMs

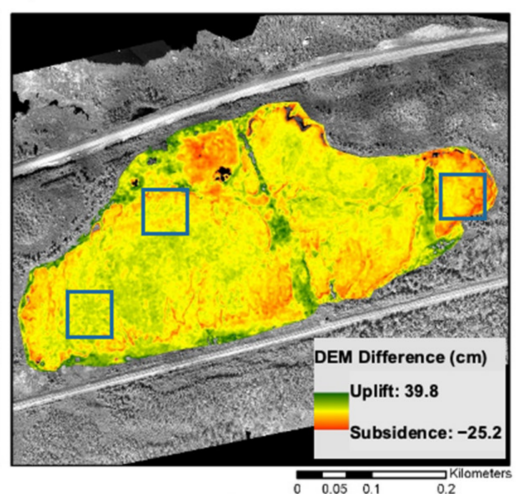

d) Zoomed-in surface motion derived from the differential DEMs
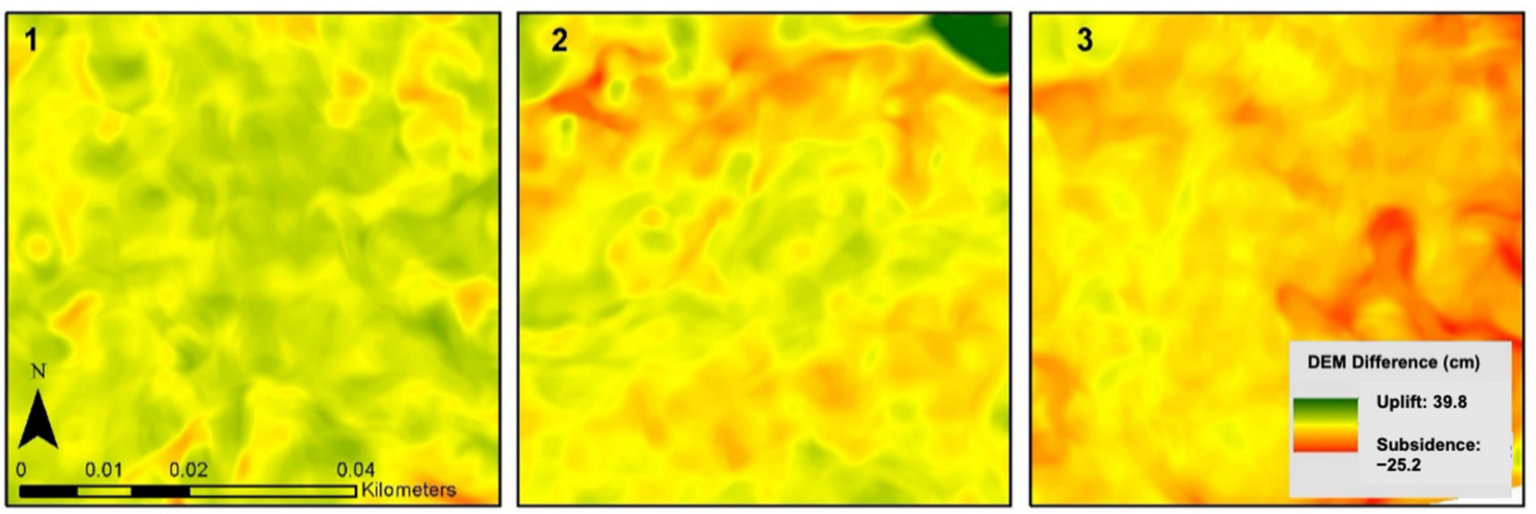

Figure 10. Surface motion (multi-annual average velocity) from 2017 to 2020 derived from (a) InSAR, (b) the vertical standard error on the InSAR for each pixel, (c) surface motion from 2017 derived from the DEMs (UAV data), and (d) the difference in surface motion for three zoomed in extracts from the differential DEMs corresponding to the blue polygons. The error on differential DEM subsidence map is $\pm 12 \mathrm{~cm}$. 


\section{Discussion}

The combination of methods used in this research provide evidence of continuous permafrost degradation that has varied over time (since the 1960s) and space (i.e., varying between the three sites of investigation as well as within sites). This is most likely in response to climatic changes in the area $[20,29,31]$. On decadal scales, the permafrost degradation rates appear to increase with time, suggesting acceleration of degradation processes in response to warmer climates and greater precipitation in the area [20]. However, due to the long intervals between the dates of the orthophotos, it is difficult to attribute changes in rates to specific climatic drivers.

On a short timescale, the UAV derived subsidence data suggest that substantial change occurred rapidly over the study areas, which has also been observed in permafrost areas such as Alaska [33,34] as well as in Siberia [51]. The potential for rapid subsidence over short timescales is also supported by the variation in the within-season range in ground motion between 2017 (low range) and 2020 (high range), estimated by the ASPIS-InSAR data (Figure 9b,c). We speculate that the high range of motion in 2020 at Stordalen was linked to two winters with soil temperatures at $20 \mathrm{~cm}$ depth close to $0{ }^{\circ} \mathrm{C}$ preceding the thaw period of 2020, because rising winter soil temperatures contribute to permafrost degradation [19]. This is in line with finding from northwest Canada, where controls on near-surface soil temperatures linked to snow conditions are a good predictor of active layer depth [17]. At this stage, the short time series of the ASPIS-InSAR limits robust comparison between subsidence rates and climate data, but the increasing Sentinel-1 data time series offer this possibility for comparison at a later date.

Subsidence rates were the highest in the raised palsa vegetation type, which was associated with the shallowest active layers, supporting our prediction that there would be a relationship between active layer depth and subsidence rates. Raised palsa also had the highest elevation within the peatlands. Together, this suggests that this vegetation types has the greatest potential for subsidence in line with findings for Canada [52]. The vulnerability of palsas to subsidence, a landform type that covers large areas at the sites, to subsidence highlights that substantial areas of these peatlands are at risk of subsidence (Figure 9, Table 2). The implication of such changes with regards to ecosystem feedbacks from permafrost thaw in peatlands, e.g., increased radiative forcing [25], are potentially severe from a climate warming perspective [53]. Therefore, the larger scale vulnerabilities of palsas to subsidence across northern Scandinavia and other regions in the sporadic and discontinuous permafrost zone, e.g., the Hudson Bay [52] and West Siberian lowlands [54] needs to be quantified.

On average, all three of the wetland sites was subsiding, indicating that permafrost thaw was impacting all three sites. This is in line with reports of deepening active layers and more extensive areas with fen vegetation types $[20,25]$, and the shrinkage of palsa plateau areas since 1960 at all three site (Figure 5). As discussed above, raised palsas had the greatest rate of subsidence, while areas with deep active layers or no permafrost had lower subsidence, supporting our hypothesis. However, all wetland vegetation types showed signs of subsidence (Figure 9a,d). This indicates that subsidence also continues after the vegetation has transitioned into a more fen-like vegetation types and the active layers are substantially deeper $(>140 \mathrm{~cm})$ or the permafrost has been lost completely. This suggests continual loss of permafrost at levels deeper than those measured in this study and/or continued physical collapse of the peat structure and vertical settlement or decomposition resulting from peat loss [55]. The rapid degradation in some areas of the Storflaket site also highlights the vulnerability of permafrost to disturbance from infrastructure such as roads, railway lines, and buried power cables.

Stordalen mire had the slowest rate of palsa shrinkage in the past, along with the shallowest active layers, but it also had the highest rates of subsidence as quantified by ASPIS-InSAR. Our interpretation is that the Stordalen mire may experience overall disintegration as climatic conditions change to such an extent that palsa mires are no longer stable, also in the eastern parts in the study region [20]. The areas of greatest subsidence 
at this site were adjacent to the lake, which we speculate may be linked to microclimatic impacts of the water body on the local energy balance. The rapid degradation rate is likely also linked to the increased length of the rapidly subsiding lateral edge (a common feature of degrading palsa) [34], as well as the formation of thermokarst in the interior areas which previously supported palsa. If this trajectory continues over time, it is perceivable that current fen areas will transition into thermokarst lakes in line with findings from northern Finland [28].

The high coherence in the InSAR data demonstrates that the data available within the thaw period was sufficient to generate a good estimate of subsidence over the study period and also within snow free periods. However, several years of data were needed to build a sufficient database in line with findings from temperate peatlands $[48,49]$. The surface motion across the peatlands were in the same range as those reported for degrading permafrost areas in Siberia, also using InSAR methods [35,37]. This suggests that the relatively low levels of ground motions reported from the InSAR at our sites are not site specific and that InSAR can detect ground motion resulting from permafrost degradation. Further, ASPIS-InSAR was able to estimate within season variability (i.e., from the range). This enables comparison across seasons and offers a tool for evaluating the climatic conditions, which result in particular surface motion trajectories and identification of areas at particular risk of subsidence.

The maximum subsidence rates measured by ASPIS-InSAR of $1.5 \mathrm{~cm}$ over four yearly summer thaw periods differed substantially from the maximum subsidence rates of $25 \mathrm{~cm}$ detected by the UAV DEMs for the same period. This difference highlights the contrasting capabilities of the two approaches. There is unavoidable spatial averaging during the processing of the Sentinel-1 data by the ASPIS-InSAR algorithm, which is likely to manifest lower subsidence rates, and if during the SAR interferometry a change in surface height during the image pairing exceeds the maximum detectable displacement $(1.2 \mathrm{~cm})$, motion will be underestimated. The differential DEMs generated from the UAV data provided highly detailed spatial outputs of subsidence of particular geomorphological features.

Indeed, this data allowed for quantification of both the lower subsidence rates found in interior palsa areas experiencing permafrost degradation and the high subsidence rates seen at the narrow front of palsa degradation, where change is most rapid (Figures 8 and 10). In some areas (e.g., the linear green features traversing the palsa plateau in Figure 8) with very dense sedge mats the ground detection was confounded with the vegetation height, resulting in artefacts suggesting areas of substantial uplift sometime in the past. The InSAR did not show this artefact but instead indicated subsidence in those areas. This corresponds to ground observation, i.e., the permafrost has been lost and the surface elevation has dropped along those linear features, which in themselves are the result of the burial of electricity cables across the palsa. Hence, the UAV data may provide a local accurate estimate of both subsidence [51] and lateral permafrost degradation. However, this method may struggle to detect ground motion over tall dense sedge vegetation and also requires substantial effort, thus limiting its application to smaller areas. In contrast, the main strength of the ASPIS-InSAR method is its superior performance in areas experiencing gradual rather than abrupt changes in surface motion over large areas [42], hence lending itself to detecting the lower levels of subsidence found across palsa plateaus experiencing permafrost degradation as well as in areas (e.g., often associated with fen-type vegetation) which have already lost their permafrost.

\section{Conclusions}

We have shown that subsidence resulting from permafrost degradation was greatest in areas with shallower active layers, i.e., areas which have the greatest potential for change, while areas further along the degradation trajectory are now experiencing lower, but still continued, subsidence rates. The combination of remote sensing approaches used here help to bridge the scale differences between the small-scale patterns of permafrost degradation and the need for circumpolar monitoring. Each approach we have used in 
this study offers different advantages, e.g., the time series data from the orthophotos are effective in demonstrating lateral erosion over long time periods, while ASPIS-InSAR can be used as a tool for detecting the subsidence resulting from recent permafrost degradation and landscape-scale understanding of the vulnerabilities linked to subsidence. The UAV differential DEM data allowed for the detection of both lateral erosion and subsidence, offering a mechanistic understanding of the process of degradation, but was sensitive to variation in vegetation height and the point cloud density. As permafrost degradation on a decadal scale is a sub-pixel property of the InSAR data, we suggest that a combination of InSAR and UAV data can be used to detect and monitor permafrost degradation across large areas while retaining mechanistic understanding of the geomorphological process of permafrost degradation.

Supplementary Materials: The following supporting information can be downloaded at: https: / / www.mdpi.com/article/10.3390/rs14030444/s1, Figure S1: Air and soil temperature (a) and precipitation and snow depth (b) data from Abisko Research Station (located within $5 \mathrm{~km}$ of the study site) for the study period, Table S1: Confusion matrix of supervised vegetation classification for Tourist St., Table S2: Confusion matrix of supervised vegetation classification for Storflaket, Table S3: confusion matrix of supervised vegetation classification for Stordalen, Table S4: Surface level range and SE during snow-free period and standard error of surface level range during the snow-free periods of 2017 and 2020 for the Tourist St., Storflaket, and Stordalen sites.

Author Contributions: S.S., D.S.B., D.J.L., J.O., M.B.S. and A.S. conceived the study; B.d.1.B.-B., A.S., D.G., C.C., A.V.B., M.L. and M.B.S. performed the data collection and analysis; A.V.B. and D.S.B. provided advice on the data analysis; S.S. wrote the manuscript. All authors have read and agreed to the published version of the manuscript.

Funding: The authors thank the Natural Environment Research Council (NE/M009106/1) for funding to S.S. and for supporting M.L.'s PhD; the University of Nottingham (IRC2020) for funds supporting the ground data collection; Carl Tryggers Stiftelse för Vetenskaplig Forskning (Tryggers Stiftelse (CTS 16: 342); and the Swedish Scientific Research Council (2017-04515), for funds awarded to J.O. and support for the UAV data collection.

Institutional Review Board Statement: Not applicable.

Informed Consent Statement: Not applicable.

Data Availability Statement: All the data relating this paper are accessible on the University of Nottingham's Research Data Repository, http:/ / doi.org/10.17639/nott.7092 (accessed on 21 December 2021), and is available on request.

Acknowledgments: We are grateful for the fieldwork support from Mattias Dalkvist and staff at Abisko Scientific Research Station. We also acknowledge that the climate data evaluation has been made by data provided by Abisko Scientific Research Station and the Swedish Infrastructure for Ecosystem Science (SITES).

Conflicts of Interest: The authors declare no conflict of interest.

\section{References}

1. Biskaborn, B.K.; Smith, S.L.; Noetzli, J.; Matthes, H.; Vieira, G.; Streletskiy, D.A.; Schoeneich, P.; Romanovsky, V.E.; Lewkowicz, A.G.; Abramov, A.; et al. Permafrost is warming at a global scale. Nat. Commun. 2019, 10, 264. [CrossRef] [PubMed]

2. Dorrepaal, E.; Toet, S.; van Logtestijn, R.S.P.; Swart, E.; van de Weg, M.J.; Callaghan, T.V.; Aerts, R. Carbon respiration from subsurface peat accelerated by climate warming in the subarctic. Nature 2009, 460, 616-619. [CrossRef]

3. Hugelius, G.A.-O.; Loisel, J.A.-O.; Chadburn, S.A.-O.X.; Jackson, R.A.-O.; Jones, M.A.-O.; MacDonald, G.; Marushchak, M.; Olefeldt, D.A.-O.; Packalen, M.; Siewert, M.A.-O.; et al. Large stocks of peatland carbon and nitrogen are vulnerable to permafrost thaw. Proc. Natl. Acad. Sci. USA 2020, 117, 20438-20446. [CrossRef] [PubMed]

4. Mishra, U.; Hugelius, G.; Shelef, E.; Yang, Y.; Strauss, J.; Lupachev, A.; Harden Jennifer, W.; Jastrow Julie, D.; Ping, C.-L.; Riley William, J.; et al. Spatial heterogeneity and environmental predictors of permafrost region soil organic carbon stocks. Sci. Adv. 2021, 7, eaaz5236. [CrossRef] [PubMed]

5. Tarnocai, C.; Canadell, J.G.; Schuur, E.A.G.; Kuhry, P.; Mazhitova, G.; Zimov, S. Soil organic carbon pools in the northern circumpolar permafrost region. Glob. Biogeochem. Cycles 2009, 23. [CrossRef] 
6. Schuur, E.A.G.; Vogel, J.G.; Crummer, K.G.; Lee, H.; Sickman, J.O.; Osterkamp, T.E. The effect of permafrost thaw on old carbon release and net carbon exchange from tundra. Nature 2009, 459, 556-559. [CrossRef] [PubMed]

7. Chaudhary, N.; Westermann, S.; Lamba, S.; Shurpali, N.; Sannel, A.B.K.; Schurgers, G.; Miller, P.A.; Smith, B. Modelling past and future peatland carbon dynamics across the pan-Arctic. Glob. Chang. Biol. 2020, 26, 4119-4133. [CrossRef]

8. Turetsky, M.R.; Abbott, B.W.; Jones, M.C.; Anthony, K.W.; Olefeldt, D.; Schuur, E.A.G.; Grosse, G.; Kuhry, P.; Hugelius, G.; Koven, C.; et al. Carbon release through abrupt permafrost thaw. Nat. Geosci. 2020, 13, 138-143. [CrossRef]

9. IPCC. The Physical Science Basis. Contribution of Working Group I to the Sixth Assessment Report of the Intergovernmental Panel on Climate Change; Cambridge University Press: Cambridge, UK, 2021.

10. Sannel, A.B.K.; Kuhry, P. Warming-induced destabilization of peat plateau/thermokarst lake complexes. J. Geophys. Res.: Biogeosci. 2011, 116, 81. [CrossRef]

11. Gibson, C.; Cottenie, K.; Gingras-Hill, T.; Kokelj, S.V.; Baltzer, J.L.; Chasmer, L.; Turetsky, M.R. Mapping and understanding the vulnerability of northern peatlands to permafrost thaw at scales relevant to community adaptation planning. Environ. Res. Lett. 2021, 16, 055022. [CrossRef]

12. Grosse, G.; Goetz, S.; McGuire, A.D.; Romanovsky, V.E.; Schuur, E.A.G. Changing permafrost in a warming world and feedbacks to the Earth system. Environ. Res. Lett. 2016, 11, 040201. [CrossRef]

13. Zuidhoff, F.S.; Kolstrup, E. Changes in palsa distribution in relation to climate change in Laivadalen, northern Sweden, especially 1960-1997. Permafr. Periglac. Processes 2000, 11, 55-69. [CrossRef]

14. Sjögersten, S.; Caul, S.; Daniell, T.J.; Jurd, A.P.S.; O'Sullivan, O.S.; Stapleton, C.S.; Titman, J.J. Organic matter chemistry controls greenhouse gas emissions from permafrost peatlands. Soil Biol. Biochem. 2016, 98, 42-53. [CrossRef]

15. Sjöberg, Y.; Marklund, P.; Pettersson, R.; Lyon, S.W. Geophysical mapping of palsa peatland permafrost. Cryosphere 2015, 9, 465-478. [CrossRef]

16. Olvmo, M.; Holmer, B.; Thorsson, S.; Reese, H.; Lindberg, F. Sub-arctic palsa degradation and the role of climatic drivers in the largest coherent palsa mire complex in Sweden (Vissátvuopmi), 1955-2016. Sci. Rep. 2020, 10, 8937. [CrossRef]

17. Zhang, Y.; Touzi, R.; Feng, W.; Hong, G.; Lantz, T.C.; Kokelj, S.V. Landscape-scale variations in near-surface soil temperature and active-layer thickness: Implications for high-resolution permafrost mapping. Permafr. Periglac. Processes 2021, 32, 627-640. [CrossRef]

18. Johansson, M.; Åkerman, J.; Keuper, F.; Christensen, T.R.; Lantuit, H.; Callaghan, T.V. Past and present permafrost temperatures in the Abisko area: Redrilling of boreholes. AMBIO 2011, 40, 558. [CrossRef]

19. Johansson, M.; Callaghan, T.V.; Bosiö, J.; Åkerman, H.J.; Jackowicz-Korczynski, M.; Christensen, T.R. Rapid responses of permafrost and vegetation to experimentally increased snow cover in sub-arctic Sweden. Environ. Res. Lett. 2013, 8, 035025. [CrossRef]

20. Åkerman, H.J.; Johansson, M. Thawing permafrost and thicker active layers in sub-arctic Sweden. Permafr. Periglac. Processes 2008, 19, 279-292. [CrossRef]

21. Sannel, A.B.K.; Hugelius, G.; Jansson, P.; Kuhry, P. Permafrost warming in a subarctic peatland-Which meteorological controls are most important? Permafr. Periglac. Processes 2016, 27, 177-188. [CrossRef]

22. Anderson, J.E.; Douglas, T.A.; Barbato, R.A.; Saari, S.; Edwards, J.D.; Jones, R.M. Linking vegetation cover and seasonal thaw depths in interior Alaska permafrost terrains using remote sensing. Remote Sens. Environ. 2019, 233, 111363. [CrossRef]

23. Kokfelt, U.; RosÉN, P.; Schoning, K.; Christensen, T.R.; FÖRster, J.; Karlsson, J.; Reuss, N.; Rundgren, M.; Callaghan, T.V.; Jonasson, C.; et al. Ecosystem responses to increased precipitation and permafrost decay in subarctic Sweden inferred from peat and lake sediments. Glob. Change Biol. 2009, 15, 1652-1663. [CrossRef]

24. Sannel, A.B.K. Ground temperature and snow depth variability within a subarctic peat plateau landscape. Permafr. Periglac. Processes 2020, 31, 255-263. [CrossRef]

25. Varner, R.K.; Crill, P.M.; Frolking, S.; McCalley, C.K.; Burke, S.A.; Chanton, J.P.; Holmes, M.E.; Null, N.; Saleska, S.; Palace, M.W. Permafrost thaw driven changes in hydrology and vegetation cover increase trace gas emissions and climate forcing in Stordalen Mire from 1970 to 2014. Philos. Trans. R. Soc. A: Math. Phys. Eng. Sci. 2022, 380, 20210022. [CrossRef]

26. Olefeldt, D.; Goswami, S.; Grosse, G.; Hayes, D.; Hugelius, G.; Kuhry, P.; McGuire, A.D.; Romanovsky, V.E.; Sannel, A.B.K.; Schuur, E.A.G.; et al. Circumpolar distribution and carbon storage of thermokarst landscapes. Nat. Commun. 2016, 7, 13043. [CrossRef] [PubMed]

27. Zhongqiong, Z.; Qingbai, W.; Guanli, J.; Siru, G.; Ji, C.; Yongzhi, L. Changes in the permafrost temperatures from 2003 to 2015 in the Qinghai-Tibet Plateau. Cold Reg. Sci. Technol. 2020, 169, 102904. [CrossRef]

28. Luoto, M.; Seppälä, M. Thermokarst ponds as indicators of the former distribution of palsas in Finnish Lapland. Permafr. Periglac. Processes 2003, 14, 19-27. [CrossRef]

29. Vallée, S.; Payette, S. Collapse of permafrost mounds along a subarctic river over the last 100 years (northern Québec). Geomorphology 2007, 90, 162-170. [CrossRef]

30. Liljedahl, A.K.; Boike, J.; Daanen, R.P.; Fedorov, A.N.; Frost, G.V.; Grosse, G.; Hinzman, L.D.; Iijma, Y.; Jorgenson, J.C.; Matveyeva, N.; et al. Pan-Arctic ice-wedge degradation in warming permafrost and its influence on tundra hydrology. Nat. Geosci. 2016, 9,312-318. [CrossRef]

31. Mamet, S.D.; Chun, K.P.; Kershaw, G.G.L.; Loranty, M.M.; Kershaw, G.P. Recent increases in permafrost thaw rates and areal loss of palsas in the Western Northwest territories, Canada. Permafr. Periglac. Processes 2017, 28, 619-633. [CrossRef] 
32. Touzi, R.; Omari, K.; Sleep, B.; Jiao, X. Scattered and received wave polarization optimization for enhanced peatland classification and fire damage assessment using polarimetric PALSAR. IEEE J. Sel. Top. Appl. Earth Obs. Remote Sens. 2018, 11, $4452-4477$. [CrossRef]

33. Douglas, T.A.; Jorgenson, M.T.; Brown, D.R.N.; Campbell, S.W.; Hiemstra, C.A.; Saari, S.P.; Bjella, K.; Liljedahl, A.K. Degrading permafrost mapped with electrical resistivity tomography, airborne imagery and LiDAR, and seasonal thaw measurements. Geophysics 2015, 81, WA71-WA85. [CrossRef]

34. Douglas, T.A.; Hiemstra, C.A.; Anderson, J.E.; Barbato, R.A.; Bjella, K.L.; Deeb, E.J.; Gelvin, A.B.; Nelsen, P.E.; Newman, S.D.; Saari, S.P.; et al. Recent degradation of interior Alaska permafrost mapped with ground surveys, geophysics, deep drilling, and repeat airborne lidar. Cryosphere 2021, 15, 3555-3575. [CrossRef]

35. van Huissteden, J.; Teshebaeva, K.; Cheung, Y.; Magnússon, R.Í.; Noorbergen, H.; Karsanaev, S.V.; Maximov, T.C.; Dolman, A.J. Geomorphology and InSAR-tracked surface displacements in an ice-rich yedoma landscape. Front. Earth Sci. 2021, 9, 587040. [CrossRef]

36. Marshall, C.; Large, D.J.; Athab, A.; Evers, S.L.; Sowter, A.; Marsh, S.H.; Sjögersten, S. Monitoring tropical peat related settlement using ISBAS InSAR, Kuala Lumpur International Airport (KLIA). Eng. Geol. 2018, 244, 57-65. [CrossRef]

37. Abe, T.; Iwahana, G.; Efremov, P.V.; Desyatkin, A.R.; Kawamura, T.; Fedorov, A.; Zhegusov, Y.; Yanagiya, K.; Tadono, T. Surface displacement revealed by L-band InSAR analysis in the Mayya area, Central Yakutia, underlain by continuous permafrost. Earth Planets Space 2020, 72, 138. [CrossRef]

38. Short, N.; LeBlanc, A.-M.; Sladen, W.; Oldenborger, G.; Mathon-Dufour, V.; Brisco, B. RADARSAT-2 D-InSAR for ground displacement in permafrost terrain, validation from Iqaluit Airport, Baffin Island, Canada. Remote Sens. Environ. 2014, 141, 40-51. [CrossRef]

39. Liu, L.; Jafarov, E.E.; Schaefer, K.M.; Jones, B.M.; Zebker, H.A.; Williams, C.A.; Rogan, J.; Zhang, T. InSAR detects increase in surface subsidence caused by an Arctic tundra fire. Geophys. Res. Lett. 2014, 41, 3906-3913. [CrossRef]

40. Park, S.-E. Variations of microwave scattering properties by seasonal freeze/thaw transition in the permafrost active layer observed by ALOS PALSAR polarimetric data. Remote Sens. 2015, 7, 17135-17148. [CrossRef]

41. Sowter, A.; Bin Che Amat, M.; Cigna, F.; Marsh, S.; Athab, A.; Alshammari, L. Mexico city land subsidence in 2014-2015 with sentinel-1 IW TOPS: Results using the intermittent SBAS (ISBAS) technique. Int. J. Appl. Earth Obs. Geoinf. 2016, 52, $230-242$. [CrossRef]

42. Bradley, A.V.; Andersen, R.; Marshall, C.; Sowter, A.; Large, D.J. Identification of typical eco-hydrological behaviours using InSAR allows landscape-scale mapping of peatland condition. Earth Surf. Dynam. Discuss. 2021, 2021, 1-28. [CrossRef]

43. Siewert, M.B.; Lantuit, H.; Richter, A.; Hugelius, G. Permafrost causes unique fine-scale spatial variability across tundra soils. Glob. Biogeochem. Cycles 2021, 35, e2020GB006659. [CrossRef]

44. Siewert, M.B. High-resolution digital mapping of soil organic carbon in permafrost terrain using machine learning: A case study in a sub-Arctic peatland environment. Biogeosciences 2018, 15, 1663-1682. [CrossRef]

45. Abisko Scientific Research Station. Meteorological data from Abisko Observatory, daily mean 2018-01-01 - 2021-09-31. 2021. Available online: https://www.jstor.org/stable/20113179 (accessed on 13 January 2021).

46. Gee, D.; Bateson, L.; Sowter, A.; Grebby, S.; Novellino, A.; Cigna, F.; Marsh, S.; Banton, C.; Wyatt, L. Ground motion in areas of abandoned mining: Application of the intermittent SBAS (ISBAS) to the Northumberland and Durham Coalfield, UK. Geosciences 2017, 7, 85. [CrossRef]

47. Cigna, F.; Sowter, A. The relationship between intermittent coherence and precision of ISBAS InSAR ground motion velocities: ERS-1/2 case studies in the UK. Remote Sens. Environ. 2017, 202, 177-198. [CrossRef]

48. Alshammari, L.; Large, D.J.; Boyd, D.S.; Sowter, A.; Anderson, R.; Andersen, R.; Marsh, S. Long-term peatland condition assessment via surface motion monitoring using the ISBAS DInSAR technique over the flow country, Scotland. Remote Sens. 2018, 10, 1103. [CrossRef]

49. Alshammari, L.; Boyd, D.S.; Sowter, A.; Marshall, C.; Andersen, R.; Gilbert, P.; Marsh, S.; Large, D.J. Use of surface motion characteristics determined by InSAR to assess peatland condition. J. Geophys. Res. Biogeosci. 2020, 125, e2018JG004953. [CrossRef]

50. Liu, L.; Zhang, T.; Wahr, J. InSAR measurements of surface deformation over permafrost on the north slope of Alaska. J. Geophys. Res.: Earth Surf. 2010, 115. [CrossRef]

51. Saito, H.; Iijima, Y.; Basharin, N.I.; Fedorov, A.N.; Kunitsky, V.V. Thermokarst development detected from high-definition topographic data in Central Yakutia. Remote Sens. 2018, 10, 1579. [CrossRef]

52. Sannel, A.B.K.; Brown, I.A. High-resolution remote sensing identification of thermokarst lake dynamics in a subarctic peat plateau complex. Can. J. Remote Sens. 2010, 36, S26-S40. [CrossRef]

53. Schuur, E.A.G.; McGuire, A.D.; Schädel, C.; Grosse, G.; Harden, J.W.; Hayes, D.J.; Hugelius, G.; Koven, C.D.; Kuhry, P.; Lawrence, D.M.; et al. Climate change and the permafrost carbon feedback. Nature 2015, 520, 171-179. [CrossRef] [PubMed]

54. Lim, A.G.; Loiko, S.V.; Pokrovsky, O.S. Sizable pool of labile organic carbon in peat and mineral soils of permafrost peatlands, western Siberia. Geoderma 2022, 409, 115601. [CrossRef]

55. Hooijer, A.; Page, S.; Jauhiainen, J.; Lee, W.A.; Lu, X.X.; Idris, A.; Anshari, G. Subsidence and carbon loss in drained tropical peatlands. Biogeosciences 2012, 9, 1053-1071. [CrossRef] 